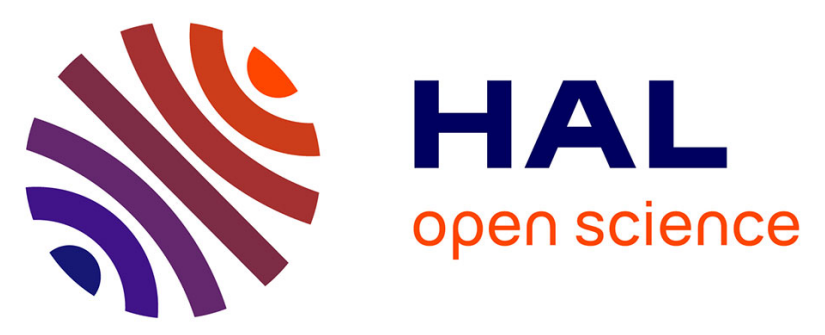

\title{
Palladium Nanosheet-Carbon Black Powder Composites for Selective Hydrogenation of Alkynes to Alkenes
}

\author{
Ahmed Ait Khouya, Housseinou Ba, Walid Baaziz, Jean Mario Nhut, Andrea \\ Rossin, Spyridon Zafeiratos, Ovidiu Ersen, Giuliano Giambastiani, Vincent \\ Ritleng, Cuong Pham Huu
}

\section{To cite this version:}

Ahmed Ait Khouya, Housseinou Ba, Walid Baaziz, Jean Mario Nhut, Andrea Rossin, et al.. Palladium Nanosheet-Carbon Black Powder Composites for Selective Hydrogenation of Alkynes to Alkenes. ACS Applied Nano Materials, 2021, 4 (2), pp.2265-2277. 10.1021/acsanm.1c00002 . hal-03450339

\section{HAL Id: hal-03450339 \\ https://hal.science/hal-03450339}

Submitted on 14 Dec 2021

HAL is a multi-disciplinary open access archive for the deposit and dissemination of scientific research documents, whether they are published or not. The documents may come from teaching and research institutions in France or abroad, or from public or private research centers.
L'archive ouverte pluridisciplinaire HAL, est destinée au dépôt et à la diffusion de documents scientifiques de niveau recherche, publiés ou non, émanant des établissements d'enseignement et de recherche français ou étrangers, des laboratoires publics ou privés. 


\section{Palladium Nanosheet-Carbon Black Powder Composites for Selective Hydrogenation of Alkynes to Alkenes}

Ahmed Aït Khouya, ${ }^{\delta}$ Housseinou Ba,${ }^{\varphi}$ Walid Baaziz, ${ }^{\S}$ Jean-Mario Nhut,${ }^{\varphi}$ Andrea Rossin, ${ }^{\omega}$ Spyridon Zafeiratos,${ }^{\varphi}$ Ovidiu Ersen,${ }^{\S}$ Giuliano Giambastiani, ${ }^{\varphi, \omega, *}$ Vincent Ritleng, ${ }^{\delta, *}$ Cuong Pham-Huи ${ }^{\varphi, *}$

¿ Université de Strasbourg, Ecole européenne de Chimie, Polymères et Matériaux, CNRS, LIMA, UMR 7042, 25 rue Becquerel, 67087 Strasbourg, France. vritleng@ unistra.fr

$\varphi$ Institute of Chemistry and Processes for Energy, Environment and Health (ICPEES), ECPM, UMR 7515 CNRS-University of Strasbourg, 25 rue Becquerel, 67087 Strasbourg Cedex 02, France. cuong.pham-huu@unistra.fr, giambastiani@unistra.fr

$\omega$ Institute of Chemistry of OrganoMetallic Compounds, ICCOM-CNR and Consorzio INSTM, Via Madonna del Piano, 10 - 50019, Sesto F.no, Florence, Italy

$\S$ Institute of Physic and Chemistry of Materials of Strasbourg (IPCMS), UMR 7504 CNRSUniversity of Strasbourg, 23 rue du Loess, 67037 Strasbourg Cedex 08, France

Abstract. Ultra-thin palladium nanosheets on carbon black grains have been straightforwardly prepared under reductant-free conditions using ultra-sonication. The asprepared composites (showing a quite unsual morphology of Pd-deposits) have been scrutinized as catalysts in the selective alkyne-to-alkene hydrogenation under mild operational conditions. Their activity, selectivity and robustness in the process are outstanding, opening new horizons for simpler synthetic procedures for this class of composites. Moreover, the tight anchorage of the large and thin metal sheets to the carbon grains of the support dramatically reduces the active phase mobility during catalysis. Besides preserving the catalyst performance, this peculiar palladium morphology strongly limits the environmental risks stemming from metal nanoparticles leaching in heterogeneous catalysts. 
Keywords: Pd-nanosheets; Sonochemical synthesis; Alkyne-to-alkene hydrogenation; Pd dual oxidic-metallic nature; chemoselectivity

\section{Introduction}

Catalytic hydrogenation is a key process in both the petrochemical industry and the production chains for pharmaceuticals and fine chemicals. In particular, the selective hydrogenation of alkynes to alkenes covers an important area of industrial production ${ }^{1,2}$ and it still represents a challenging task for many research teams active in the area of hydrogenation catalysis. $^{3}$ Alkenes find a high number of applications, spanning from intermediates in the synthesis of fine chemicals to building blocks for polymers production. However, olefins production from alkynes requires catalysts able at hydrogenating the triple bond and hampering at the same time over-hydrogenation/reduction paths towards completely saturated hydrocarbons (alkanes). In addition, these catalysts should limit the undesired and uncontrollable double-bond chain-walking phenomena (isomerization). Supported catalysts containing palladium nanoparticles $(\mathrm{Pd} \mathrm{NPs})^{4-8}$ are among the best candidates in terms of activity, although they often suffer from moderate selectivity towards the target product. ${ }^{9}$

Typical approaches used to improve their chemoselectivity ${ }^{10}$ rely on the modification of NPs support by the addition of $\mathrm{N}-$, P- or S-containing ligands ${ }^{11-13}$ or on the co-doping of the catalytically active metal with a less active one. ${ }^{11,14,15}$ The most emblematic example in this domain is represented by the Lindlar catalyst, where $\mathrm{Pd} / \mathrm{CaCO}_{3}$ is partially "poisoned" by the addition of lead $(\mathrm{Pb})$ in traces and quinoline. However, the presence of a toxic metal like lead represents a serious limit for its eco-sustainable use in the alkyne-to-alkene reduction process. Another effective approach relies on the "active site isolation" strategy, dealing with the development of single atom-based catalysts. ${ }^{16,17}$ Whatever the nature of the applied strategy, they generally require relatively complex and costly synthetic solutions that may compromise the process sustainability and its large scale implementation. Therefore, the quest for easy-to- 
make, highly efficient and selective catalysts working at moderate $\mathrm{H}_{2}$ pressure without extra ligands or co-catalysts is a matter of intense research activity worldwide.

Sonochemistry is a technique based on an acoustic cavitation process where micrometer bubbles are formed in a liquid, grow and finally collapse implosively. ${ }^{18}$ The bubbles' collapse produces the evolution of an intense energy with local temperatures raising that can reach up to $5273 \mathrm{~K}$ and local pressures exceeding hundreds of atmospheres. At the same time, the sonicated environment is featured by an extremely high cooling rate (estimated around 109 $\mathrm{K} / \mathrm{s}){ }^{18,19}$

Dynamics of acoustic cavitation growth and collapse are deeply influenced by the specific local environment. Indeed, the cavity collapse in a homogeneous liquid phase is extremely different from that occurring at a liquid-solid interface. The synthesis of multiwalled carbon nanotubes decorated with palladium nanoparticles by an ultrasonic cavitation approach (using either pure C-carriers or N-doped C-networks) has been recently described by Vanyorek et $a l .^{20}$ Their straightforwardly prepared Pd-based composites displayed high catalytic hydrogenation performance in the nitrobenzene-to-aniline conversion, already at low reaction temperatures. The authors' conclusions on the ability of the adsorbent carrier to reduce - under ultrasonic cavitation - the metal ion precursor, prompted us to study the effect of this technique for the palladium deposition on simple carbon black (Vulcan XC-72) suspended in an oxygen-lean water medium.

Quite unexpectedly, the as-prepared composite showed the generation of metal deposits in the form of irregularly shaped ultra-thin palladium nanosheets, wrapped to carbon grains. Despite of the unconventional morphology of palladium deposits, these composites have unveiled unexpected performance in catalysis, showing activity in the selective alkyne-toalkene hydrogenation comparable or even higher than those claimed for the benchmark 
Lindlar catalyst or other more costly and less easy to be prepared nanoparticle-based or single-atom-based catalysts of the state-of-the-art. ${ }^{16,17}$

Accordingly, the work describes a straightforward and fully reproducible catalyst preparation methodology based on the ultrasonication of an aqueous suspension of $\mathrm{CB}$ in the presence of a commercial $\mathrm{Pd}^{\mathrm{II}}$ salt followed by a low temperature $(383 \mathrm{~K})$ evaporation/drying phase for the solid catalyst recovering. At odds with more conventional preparation methods, this protocol does not require any calcination/reduction treatment to get a highly performing and robust nanostructured hydrogenation system. Thus, the applied procedure shows a significant reduction of many energy and reagent wastes typically encountered in classical synthetic approaches towards the preparation of shape- and size-controlled metal particles at the nanoscale to be engaged as selective hydrogenation catalysts. Finally, the absence of small palladium nanoparticles and their replacement by ultra-thin metal nanosheets wrapped to carbon grains reduce the mobility of the catalytically active phase from the support, thus providing a robust and re-usable catalytic system for the process.

\section{Experimental section}

\subsection{Materials and characterization methods.}

Unless otherwise stated, all commercial reagents, intermediates and solvents were used as received without any further purification. 3-Hexyne (99\% - 306894), phenylacetylene (98\% 11,770-6), palladium 10 wt.\% on activated carbon $\left({ }^{10} \mathrm{Pd} / \mathrm{AC}\right)$ (CAS n. 20,569-9), $\left[\mathrm{PdCl}_{2}\left(\mathrm{NH}_{3}\right)_{4}\right] \cdot \mathrm{H}_{2} \mathrm{O}(\geq 99.9 \%$ - CAS n. 323438) were purchased from Sigma-Aldrich. 1Heptyne (99\% - CAS n. A11130) was provided by Alfa Aesar. Commercial carbon black (Vulcan XC-72) in the form of powder was received from Fluka and used as such (without any pre-treatment) for the synthesis of Pd-based composites. 
Transmission Electron Microscopy (TEM) analyses was carried out on a JEOL 2100F FEG S/TEM working at $200 \mathrm{kV}$ accelerated voltage, equipped with a probe corrector for spherical aberrations. The analysed sample was dispersed by ultrasounds in ethanol (for 5 minutes) and a drop of the suspension was casted on a copper grid covered with a holey carbon membrane, evaporated to dryness and used for observation. For the analysis by high angular annular dark field (HAADF) in scanning transmission electron microscopy (STEM) mode, a spot size of $0.13 \mathrm{~nm}$, a current density of $140 \mathrm{pA}$ and a camera focal length of $8 \mathrm{~cm}$, corresponding to the inner and outer diameters of the annular detector of about 73 and 194 mrad, were used.

Elemental mapping, i.e.: carbon $(\mathrm{C})$, oxygen $(\mathrm{O})$ and palladium $(\mathrm{Pd})$, was carried out by energy dispersive X-ray spectroscopy (EDX) using a silicon drift detector (SDD) with a sensor size of $60 \mathrm{~mm}^{2}$. For electron tomography analysis, the sample was dispersed in ethanol and deposited on a 200-mesh holey carbon grid containing Au NPs of $5 \mathrm{~nm}$ used during the measurement as seeds to align the tilted images. The grid was mounted on a tomographic single-tilt sample holder. The tilt series were acquired in HAADF mode between $70^{\circ}$ and $-70^{\circ}$ from the initial position of sample using $2^{\circ}$ increments through the tomography plug-in of the Digital Micrograph software, which controls the specimen tilt step-by-step, the defocusing and the specimen drift. The inner radius of the HAADF detector was about $40 \mathrm{mrad}$. Image alignment was performed through fiducial-less methods, namely a combination of crosscorrelation and center of mass methods using IMOD software. ${ }^{21}$ The reconstructed 3D volumes were obtained using the algebraic reconstruction technique (ART) ${ }^{22}$ implemented in the TomoJ plugin ${ }^{23}$ working in the ImageJ software. Segmented 3D models were constructed using the displaying capabilities and the isosurface rendering method in the Slicer software.

Inductively Coupled Plasma-Atomic Emission Spectrometry (ICP-AES): the palladium loading was fixed by ICP-AES after complete acidic mineralization of the sample $\left({ }^{0.9} \mathrm{Pd} / \mathrm{CB}\right)$, 
using an Optima 2000 PerkinElmer Inductively Coupled Plasma (ICP) Dual Vision instrument.

Powder X-ray Diffraction (PXRD) measurements were carried out on a Bruker D-8 Advance diffractometer equipped with a Vantec detector ( $\mathrm{Cu} \mathrm{K} \alpha$ radiation) working at $40 \mathrm{kV}$ and $40 \mathrm{~mA}$. X-ray diffractograms were recorded in the $20-80^{\circ} 2 \theta$ region at room temperature in air. The active metallic surface area of ${ }^{0.9} \mathrm{Pd} / \mathrm{CB}$ was measured by $C O$ chemisorption on a Micromeritics ${ }^{\circledR}$ ASAP 2020 instrument. The catalyst $(0.35 \mathrm{~g})$ was degassed at $623 \mathrm{~K}$ for 15 min under high vacuum $\left(10^{-6}\right.$ torr) before being cooled to $308 \mathrm{~K}$ under Ar. After purging the sample with $\mathrm{H}_{2}$ for additional $2 \mathrm{~h}$ at $623 \mathrm{~K}$, chemisorption was run at $308 \mathrm{~K}$. The value of the metal dispersion, the crystallite size and the metal active surface area was provided directly by the instrument, assuming a $\mathrm{CO} / \mathrm{Pd}$ average chemisorption stoichiometry of $2 .^{24,25}$

$N_{2}$ adsorption-desorption measurements were carried out on a Micromeritics ${ }^{\circledR}$ ASAP 2020 instrument at the liquid $\mathrm{N}_{2}$ temperature $(77 \mathrm{~K})$ and relative pressures between 0.06 and $0.99 \mathrm{P} / \mathrm{P}_{0}$. Each sample was outgassed at $473 \mathrm{~K}$ under ultra-high vacuum $\left(10^{-6}\right.$ torr) for $12 \mathrm{~h}$ before the analysis in order to desorb moisture and adsorbed volatile species.

X-ray Photoelectron Spectroscopy (XPS) was carried out in an ultrahigh vacuum (UHV) spectrometer equipped with a VSW Class WA hemispherical electron analyzer and a monochromatic Al Ka X-ray source (1486.6 eV). Survey and high-resolution spectra were recorded in constant pass energy mode (90 and $22 \mathrm{eV}$, respectively). Binding energies were calibrated by referring to the $\mathrm{C} 1 \mathrm{~s}$ peak at $284.4 \mathrm{eV}$. Shirley-type background subtraction and fitting of the spectra were done with the software package Casa XPS vs. 2.3. The Pd $3 d$ peak was fitted using two doublets (i.e. $\mathrm{Pd}^{0}$ and $\mathrm{Pd}^{\mathrm{II}}$ ) representing metallic and oxidized Pd species. Asymmetric and symmetric peak shapes were used to fit the metallic and oxidized Pd components respectively. For the fitting of $\mathrm{C} 1 s$ five components were used corresponding to the various chemical states of the carbon support. 
Gas-chromatographic (GC) measurements were performed on a Varian $3800 \mathrm{CX}$ gas chromatographer equipped with a PONA column and a Flame Ionization Detector (FID). The retention times and GC response in terms of area versus concentration of the reagents and products were calibrated by using pure components diluted in an ethanol solution at various concentrations. The conversion and product distribution were calculated from the GC results.

\subsection{Ultrasonication-assisted preparation of ultra-thin Pd-nanosheets on carbon-} black $\left({ }^{0.9} \mathbf{P d} / \mathbf{C B}\right)$. Carbon black $(\mathrm{CB})(1 \mathrm{~g})$ was dispersed in distilled water $(100 \mathrm{~mL})$ and underwent ultrasonication in a tip sonicator $(80 \mathrm{~W}, 50 \mathrm{~Hz})$ at room temperature for $20 \mathrm{~min}$. Afterwards, $\left[\mathrm{PdCl}_{2}\left(\mathrm{NH}_{3}\right)_{4}\right] \cdot \mathrm{H}_{2} \mathrm{O}(25 \mathrm{mg}, 1 \mathrm{wt} \%$ in $\mathrm{Pd} v \mathrm{~s}$. mass of $\mathrm{CB})$ was added to the suspension in one portion and the mixture underwent sonication (80 watt, $50 \mathrm{~Hz}$ ) for additional 10 minutes. The suspension of the composite was then evaporated to dryness at ambient pressure and $383 \mathrm{~K}$ for $12 \mathrm{~h}$ to afford $\mathrm{Pd} / \mathrm{CB}$ in the form of black powder. ICP-AES analysis of the latter confirmed a Pd content of $9.24 \mathrm{~g} / \mathrm{kg}$, i.e. of $0.924 \mathrm{wt} . \%$. Accordingly, it will be quoted hereafter as follows: ${ }^{0.9} \mathrm{Pd} / \mathrm{CB}$, where 0.9 stands for the wt.\% of Pd deposits and $\mathrm{CB}$ indicates carbon black (Vulcan XC-72) as the support.

2.3 General procedure for the catalytic semi-hydrogenation of alkynes-to-alkenes with ${ }^{0.9} \mathrm{Pd} / \mathrm{CB}$ and the benchmark ${ }^{10} \mathrm{Pd} / \mathrm{AC}$ hydrogenation catalyst.

A proper catalyst amount (i.e. $100 \mathrm{mg}$ of ${ }^{0.9} \mathrm{Pd} / \mathrm{CB}$ or $9.3 \mathrm{mg}$ of ${ }^{10} \mathrm{Pd} / \mathrm{AC}$ ) was suspended in ethanol $(20 \mathrm{~mL})$ and activated by bubbling $\mathrm{H}_{2}$ at room temperature for 30 min under a constant reductant flow rate $(5.0 \mathrm{~mL} / \mathrm{min})$. Afterwards, $1.52 \mathrm{mmol}$ of a selected alkyne $(\mathrm{Pd}=$ $0.6 \mathrm{~mol} \% \mathrm{vs}$. substrate) were added in one portion by syringe to the stirred suspension (600 rpm), and $T_{0}$ reaction time was fixed. During the reaction course, $\mathrm{H}_{2}$ was constantly fed at ambient conditions (room temperature and atmospheric pressure) and constant flow rate (2.5, 5.0 or $13 \mathrm{~mL} / \mathrm{min}$ ). Under these conditions, the semi-hydrogenation kinetic was monitored by 
sampling the reaction medium $(50 \mu \mathrm{L})$ at constant times. Each sample was diluted with ethanol (3 mL), filtered through a Celite ${ }^{\circledR}$ pad and analyzed by GC.

In a control experiment conducted for highlighting the excellent selectivity in the semihydrogenation of phenylacetylene (PA) to styrene (ST) with ${ }^{0.9} \mathrm{Pd} / \mathrm{CB}$, we followed the abovedescribed procedure except for the use of a 37/63 mixture of PA $(0.61 \mathrm{mmol})$ and ST (0.91 mmol), respectively, as reagents at $T_{0}$.

$2.3 .1^{0.9} \mathrm{Pd} / \mathrm{CB}$ recovering and reuse in successive semi-hydrogenation runs. In a typical catalyst' recycling test, a suspension of ${ }^{0.9} \mathrm{Pd} / \mathrm{CB}(100 \mathrm{mg})$ in ethanol $(20 \mathrm{~mL})$ was activated by $\mathrm{H}_{2}$ bubbling $(5.0 \mathrm{~mL} / \mathrm{min})$ for $30 \mathrm{~min}$ at room temperature. Afterwards, 3-hexyne $(1.52$ mmol) was added in one portion and the reaction medium was stirred and bubbled with $\mathrm{H}_{2}$ for 50 min under ambient conditions (room temperature and ambient pressure) at a constant flow rate $(5.0 \mathrm{~mL} / \mathrm{min})$. The reaction course was monitored after $50 \mathrm{~min}$ by sampling the reaction medium and analyzing it as reported above. The catalytic powder $\left({ }^{0.9} \mathrm{Pd} / \mathrm{CB}\right)$ was recovered from the reaction medium by centrifugation at $5000 \mathrm{rpm}$ for $8 \mathrm{~min}$ and the supernatant mother liquor was removed. The solid residue was then washed with ethanol (3 x $20 \mathrm{~mL})$ and centrifuged again to separate it from the liquid phase. After three-fold washing-centrifugation cycles, the recovered solid was oven dried at $383 \mathrm{~K}$ for $1 \mathrm{~h}$ and re-used in catalysis as described above.

2.3.2 Leaching test. A separate catalytic run was used to estimate the leaching of the metal active phase throughout the hydrogenation path. To this aim a first catalytic semihydrogenation of 3-hexyne $(1.52 \mathrm{mmol})$ was carried out as reported above (see $\S 2.3 .1)$ with $100 \mathrm{mg}$ of ${ }^{0.9} \mathrm{Pd} / \mathrm{CB}$. After $50 \mathrm{~min}$ run, the catalyst $\left({ }^{0.9} \mathrm{Pd} / \mathrm{CB}\right)$ was separated from the reaction medium by filtration over a Celite ${ }^{\circledR}$ pad and the filtrate was analyzed by GC to estimate the alkyne conversion and the product selectivity. The separated mother liquor was then treated with an additional amount of 3-hexyne $(1.52 \mathrm{mmol})$ and the clear solution was maintained 
under stirring, at room temperature and constant $\mathrm{H}_{2}$ flow rate $(5.0 \mathrm{~mL} / \mathrm{min})$ for further $50 \mathrm{~min}$. Afterwards, the sampling of the solution was analyzed by GC and it did not show any appreciable conversion of the additional amount of 3-hexyne or any change in the selectivity of the reaction products observed at the end of the first catalytic run. This experiment, combined with the complete retention of catalyst conversion and selectivity in successive catalytic runs (vide infra $\S 3.4$ ), confirmed the heterogeneous nature of the process and hence the negligible amount of any catalytically active Pd species leached from the carbon support and accidentally engaged in the hydrogenation process.

\section{Results and Discussion}

\section{$3.1^{0.9} \mathrm{Pd} / \mathrm{CB}$ catalyst characterization}

A representative configuration of the sonicator setup employed for the preparation of

${ }^{0.9} \mathrm{Pd} / \mathrm{CB}$ is summarized in Figure 1A. Typical STEM micrographs acquired on several grains of ${ }^{0.9} \mathrm{Pd} / \mathrm{CB}$ are shown in Figure 1B-G and Figures S1-S2, respectively. Bright field STEM images of the pristine carbon black (CB) at various magnifications are reported in Figure S3. High-resolution XPS analysis of the C $1 s$ core region of $\mathrm{CB}$ along with $\mathrm{N}_{2}$ adsorptiondesorption isotherm linear plot (BET) are reported in Figure S4 and Figure 4B (vide infra), respectively, for the sake of completeness. TEM analysis highlights the presence of well dispersed and highly waved Pd deposits with entangled structures around the support's carbon grains (Figures 1B-E and Figures S1-S2). HR STEM images (Figure 1F-G) finally account for highly crystalline metal deposits showing typical interplanar distances of 0.24 and $0.20 \mathrm{~nm}$ that well-match with those of Pd (111) and Pd (100) planes, respectively. ${ }^{26}$ These images also unveil the polycrystalline character of the formed Pd deposits. In particular, two randomly oriented palladium crystallites (delimitated by the white line) are clearly observed (Figure 1G). This polycrystalline nature is also visible (on a larger scale), in the Fast Fourier 
Transform (FFT) pattern outlined on Figure S5. In this sequence of high-resolution images, the individual crystallite contributions raising from the palladium deposits and those from the underlying graphitic layers of CB are clearly visible.

To get additional insights on the metal distribution and its crystallinity, HR STEM analysis was deliberately acquired on different areas of the same flake, by selecting portions apparently featured by different metal thickness (Figure S6). Accordingly, on areas with very low image contrast (green square), where only few layers of palladium are formed in direct contact with the carbon support, very small metal clusters without any appreciable crystallographic order (FFT pattern in inset) are visible. On the other hand, where palladium thickness remains quite small, but it appears more contrasted and thicker (e.g. red square portion), a more pronounced tendency to generate ordered crystallites is unambiguously observed. As claimed above, the crystallographic interplanar distances measured on these marked portions are consistent with the Pd (111) and Pd (100) planes. The different crystallinity degree measured on two areas of the same flake is tentatively ascribed to a different growth of the metal deposits. When it occurs directly at the CB surface, the lattice mismatch between carbon and palladium translates into heteroepitaxially grown palladium clusters. Such a support-induced disorder is partially compensated where Pd become thicker and where homoepitaxially and crystallographically ordered deposits grow. ${ }^{27-29}$

The XRD profile of ${ }^{0.9} \mathrm{Pd} / \mathrm{CB}$ was consistent with the prevalent generation of $\mathrm{Pd}^{0}$ deposits whose distinctive reflections were characteristic for face centered cubic (fcc) Pd structures ${ }^{30}$ (Figure S7). A minor component ascribed to $\mathrm{PdO}$ is also detected with the reflection from the (002) plane that appears at the angular position of $\sim 33.8$ degrees. Thickness of metal deposits changes from side to side of the same metallic flake. This is likely due to the presence of alternate thin and thick metallic layers originated from nanosheets folding or twisting phenomena. In the attempt to get additional information on the morphology of waved $\mathrm{Pd}$ 
nanosheets, metal deposits were additionally studied by Electron Tomography (Figure 2). ${ }^{31-33}$

The direct analysis of a 3D model obtained from the calculated reconstruction of a selected Pd flake has confirmed the presence of shapeless tridimensional networks, formed by relatively large and thin nanosheets wrapped around carbon templates.

The 3D metal morphology presents unique distinctive features characterized by randomly curved layouts fixed at the surface of CB particles (see slices in Figure 2), with multi-faceted orientations at their far ends. An appropriate space orientation of the 3D metal volume has allowed a rough estimation of the nanosheets thickness ranging between 2 and $5 \mathrm{~nm}$ (Figure 2). Electron tomography data give a mean specific surface area of a representative palladium flake close to $5.65 \mathrm{~m}^{2} \mathrm{~g}^{-1}$.
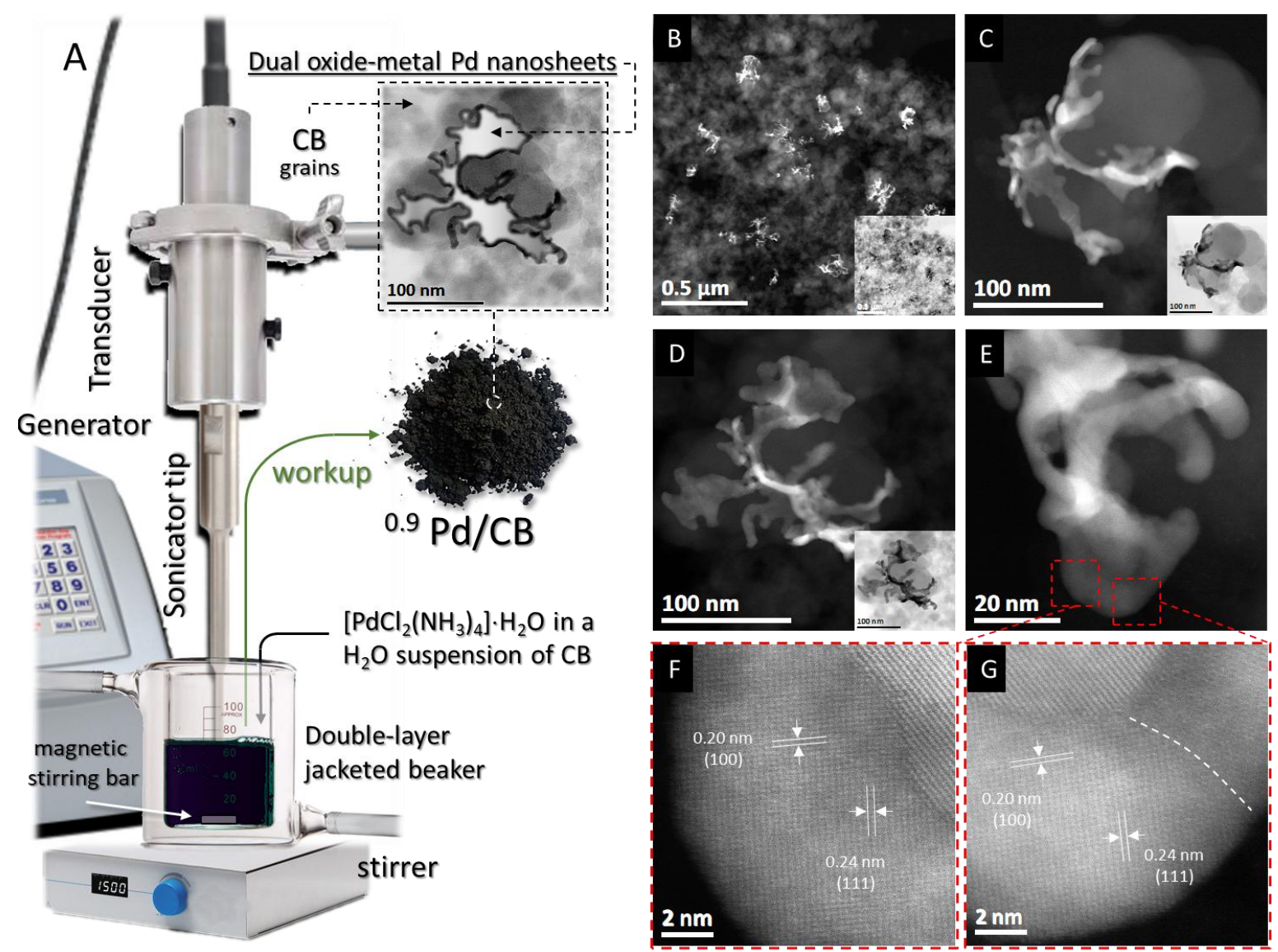

Figure 1. A) Schematic representation of the sonicator setup and product composition. B-D) HAADF STEM micrographs (in inset the corresponding bright field images) of some representative grains of ${ }^{0.9} \mathrm{Pd} / \mathrm{CB}$ sample showing the typical morphologies of palladium nanosheets wrapped to activated carbon spheres. E-G) High resolution HAADF STEM micrographs illustrating the crystalline nature of palladium nanosheets, with some crystallographic planes annotated in white on the images. 
Palladium nanosheets appeared homogeneously distributed on the whole scanned area (Figure 1B and Figures S1A-B) without showing larger aggregates or the occurrence of specific metal segregation phenomena. STEM-EDS elemental mapping of ${ }^{0.9} \mathrm{Pd} / \mathrm{CB}$ was also recorded, and results are outlined in Figure 3.

Noteworthy, oxygen $(\mathrm{O})$ map (Figure 3D) reveals the presence of an extensively oxidized C-network whose generation was likely attributed to the severe conditions encountered by CB throughout the ultrasonication treatment (see experimental section).
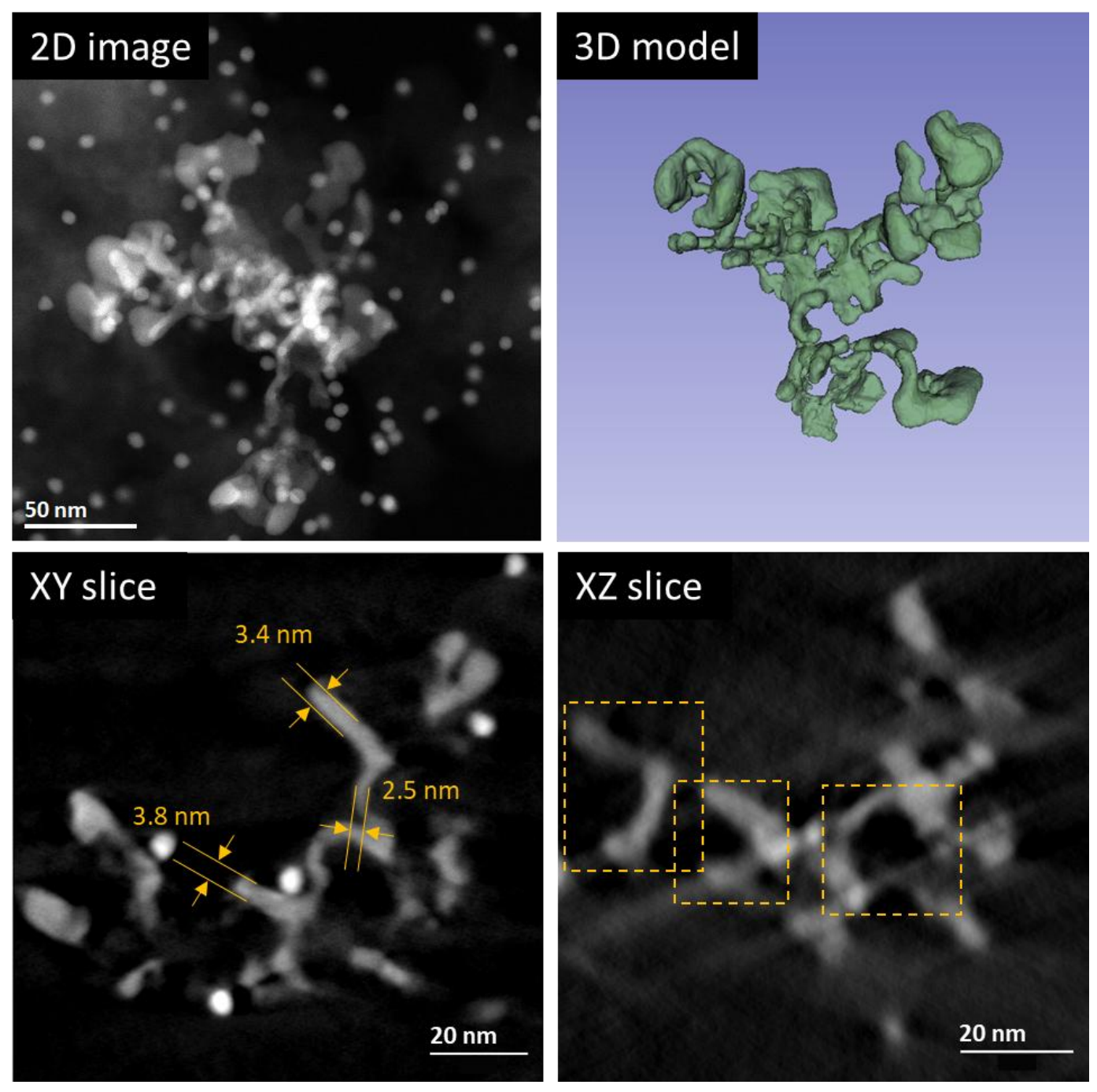

Figure 2. 3D analysis by STEM-HAADF tomography of a typical ${ }^{0.9} \mathrm{Pd} / \mathrm{CB}$ particle: one of the images from the tilt series used to reconstruct the volume (top left), the 3D model of the reconstructed volume for the $\mathrm{Pd}$ constituent (top right) and two orthogonal slices 
(perpendicular and parallel to the projection direction which is the electron beam axis) (bottom). Some typical thicknesses of the Pd nanosheets are also illustrated in the figure.

Although any conclusion on the nature of the $\mathrm{Pd}^{\mathrm{II}}$ reduction mechanism remains on a mere speculative ground, it is reasonable to claim a dual role for the oxidized carbon black in the process: 1) it creates oxygenated and preferential anchoring sites for Pd particles nucleation and growth; 2) it provides an electron reservoir for $\mathrm{Pd}^{\mathrm{II}}$ reduction through the overoxidation of its O-containing functional groups.
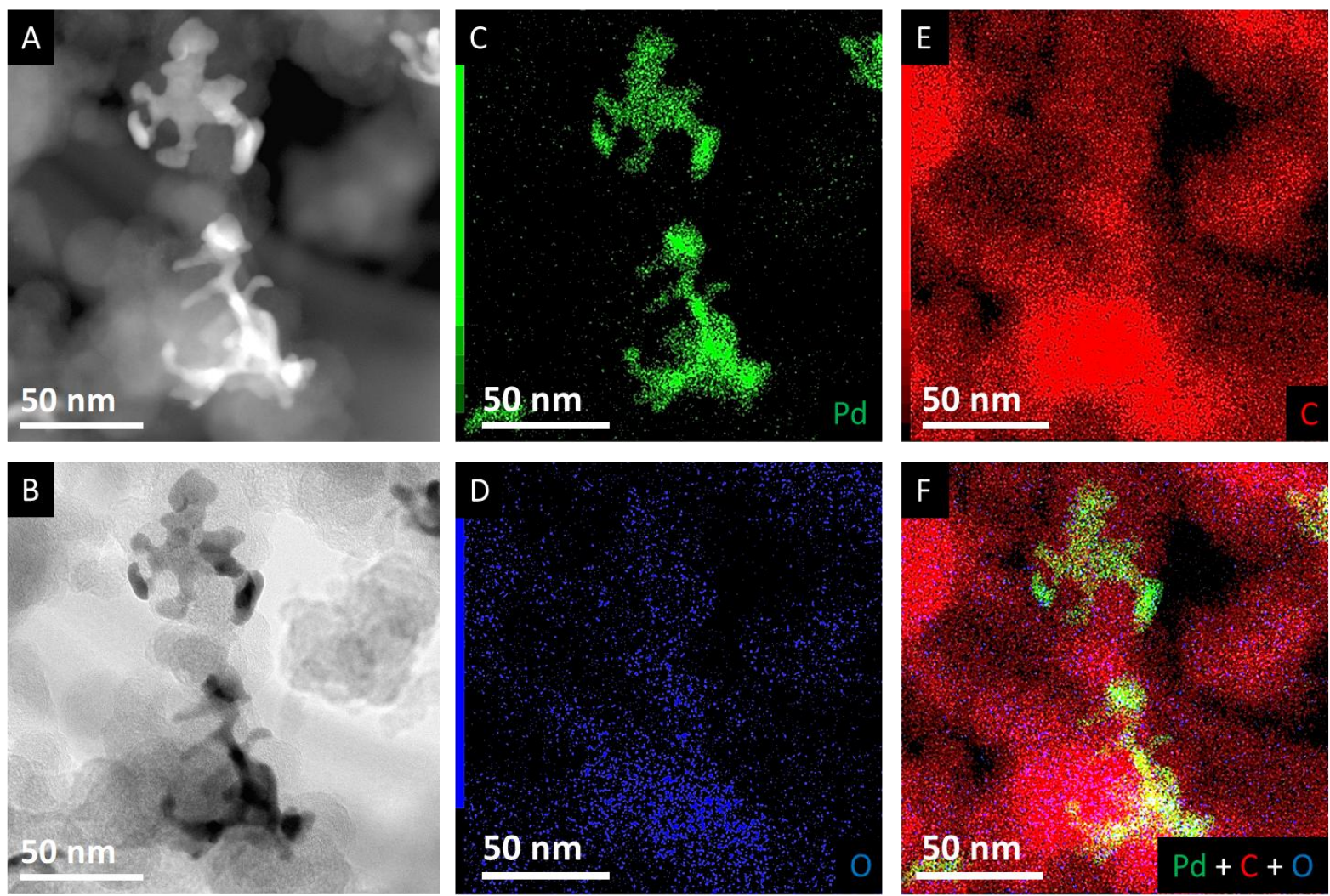

Figure 3. A) Annular dark field STEM image of typical ${ }^{0.9} \mathrm{Pd} / \mathrm{CB}$ particles obtained by sonication followed by an oven drying at $403 \mathrm{Kin}$ air. B) The corresponding bright field STEM image. C-F) Elemental maps obtained by EDX spectroscopy, in STEM mode, of Pd, O and $\mathrm{C}$ on the analyzed grains of ${ }^{0.9} \mathrm{Pd} / \mathrm{CB}$ shown on the images $\mathrm{A}$ and $\mathrm{B}$.

This redox aptitude of oxidized carbons is already known in sugar chemistry where reducing carbohydrates (typically polysaccharides) behave similarly in the presence of a wide variety of metal salt precursors. ${ }^{34-37}$ 
If high local temperature gradients generated during cavitation collapse may favor the $\mathrm{Pd}^{\mathrm{II}}$-to- $\mathrm{Pd}^{0}$ reduction, ${ }^{38}$ shock waves resulting from cavitation in liquid-solid slurries are known to produce high-velocity metal inter-particle collisions that induce melting. ${ }^{19}$ This phenomenon causes an extensive coalescence of metal particles, thus giving rise to the observed morphology of the Pd deposits in the composite (Figure 1B-G and Figure S2).

X-Ray photoelectron spectroscopy (XPS) and $\mathrm{N}_{2}$ adsorption-desorption isotherm linear plot (BET) of ${ }^{0.9} \mathrm{Pd} / \mathrm{CB}$ have also been recorded to complete the catalyst characterization. As Figure S8 shows, the XPS survey scan spectrum of the catalyst indicates the presence of O, $\mathrm{Pd}$ and $\mathrm{C}$ elements and rules out the presence of impurities. The high-resolution $\mathrm{Pd} 3 d \mathrm{XPS}$ core level region (Figure 4A) clearly accounts for two distinct components ascribed to metallic $\mathrm{Pd}^{0}$ and $\mathrm{Pd}^{\mathrm{II}}$ species with binding energies at $3 \mathrm{~d}_{5 / 2}=335.5 \mathrm{eV}, 337.5 \mathrm{eV}$ and $3 \mathrm{~d}_{3 / 2}=$ $340.9 \mathrm{eV}, 343.1 \mathrm{eV}$, respectively. ${ }^{39}$
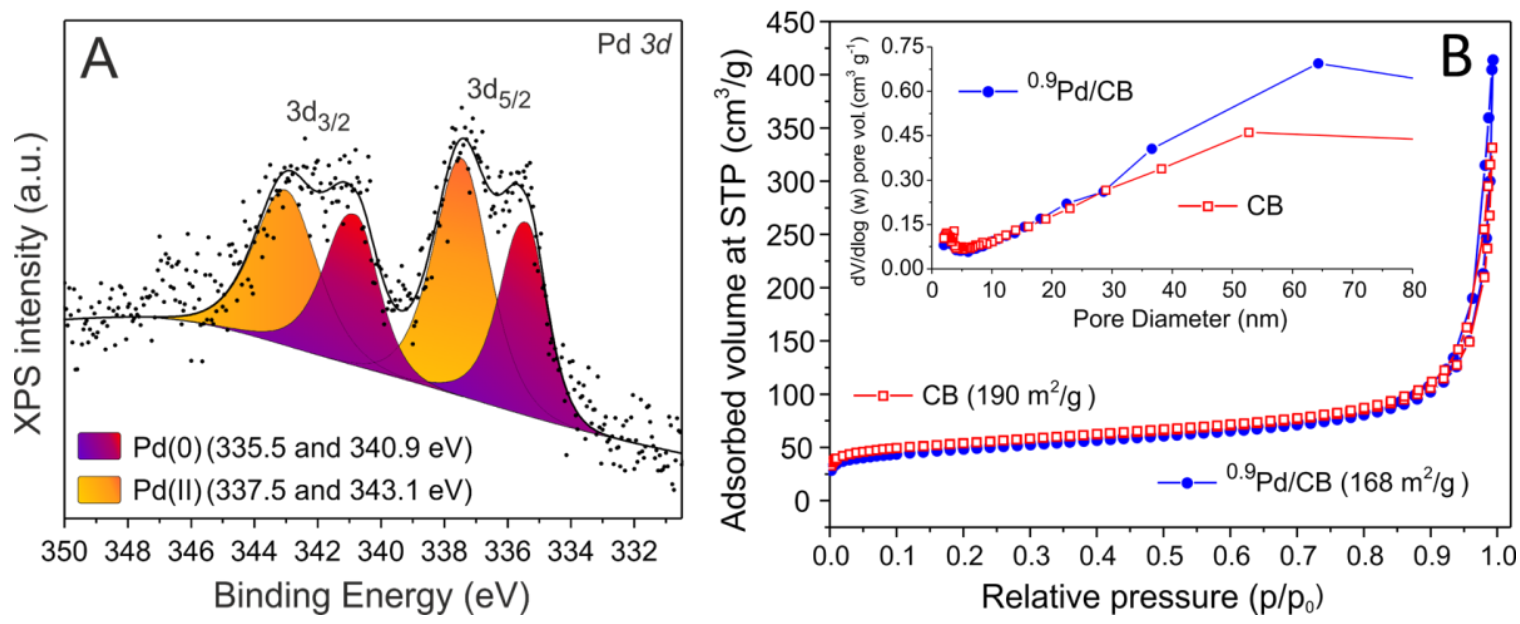

Figure 4. A) High resolution XPS spectrum of Pd $3 d$ core level region of a freshly prepared ${ }^{0.9} \mathrm{Pd} / \mathrm{CB}$. B) $\mathrm{N}_{2}$ adsorption-desorption isotherm linear plot (BET) of ${ }^{0.9} \mathrm{Pd} / \mathrm{CB}(-\bullet)$ plain $\mathrm{CB}$ ( - -) at comparison. Inset refers to the pore volume distribution $[\mathrm{dV} / \mathrm{d} \log (\mathrm{w})]$ for the two materials measured by the $\mathrm{BJH}$ desorption branch.

According to literature precedents, ${ }^{40}$ these authors cannot exclude the existence of strong bonding interactions at the $\mathrm{Pd}-\mathrm{C}$ interface throughout the $\mathrm{O}$-containing functionalities at the oxidized surface of the carbon carrier. However, the relatively high concentration of $\mathrm{Pd}^{\mathrm{II}}$ 
species (around 60\%) from the Pd $3 d$ XPS spectrum (Figure 4A) together with the moderate intensity of PdO reflection planes from XRD analysis (Figure S7) and the relatively high thickness estimated for the Pd-deposits (from 2 to $5 \mathrm{~nm}$, Figure 2), suggest that $\mathrm{Pd}^{\mathrm{II}}$ species are essentially due to a partial oxidation of the outer metal surface.

The co-existence of palladium in two stable oxidation states can be regarded as a naturally occurred "poisoning" of the palladium catalyst itself. Accordingly, such a mixed PdO-Pd surface composition can be invoked to explain the high catalyst selectivity towards challenging semi-hydrogenation reactions like those described hereafter in the manuscript. This finding is in line with very recent outcomes from the literature where the dual oxidicmetallic nature of noble metal-based catalysts, enables a favourable synergy between the two phases. It is the case of the $\mathrm{CO}$ oxidation reaction at low temperature on $\mathrm{Pt} / \mathrm{CeO}_{2}$ catalysts ${ }^{41}$ as well as that of methane oxidation on Pd catalysts ${ }^{42}$ where the presence of both oxidized and metallic species enhances the catalysts performance. In addition, a recent quantum-chemical modelling of the adsorption interactions of a model alkyne (PA, phenylacetylene) and its semi-hydrogenated counterpart (ST, styrene) at the $\mathrm{Pd}^{0}$ surface ${ }^{43}$ has pointed out the higher selectivity of PA adsorption on Pd (111) and Pd (100) facets that matches well with our HR STEM evidences (Figure 1E-G) on the nature of the crystalline metal deposits of ${ }^{0.9} \mathrm{Pd} / \mathrm{CB}$. The same in-silico study has also claimed an almost total absence of adsorption selectivity on edge sites of $\mathrm{Pd}$ particles $^{43}$ (if not a slightly higher adsorption selectivity for ST), thus concluding that the higher the Pd particle size the higher the selectivity of PA-to-ST semihydrogenation in the process. Both aspects match well with the nature of $\mathrm{Pd}$ nanosheets available on ${ }^{0.9} \mathrm{Pd} / \mathrm{CB}$ and the observed selectivity in PA-to-ST hydrogenation (vide infra).

As far as the ${ }^{0.9} \mathrm{Pd} / \mathrm{CB}$ specific surface area (SSA) is concerned, the composite shows a classical Type II isotherm ${ }^{44}$ (Figure 4B) and its SSA value $\left(168 \mathrm{~m}^{2} / \mathrm{g}\right.$ ) ranks very close to that of the plain $\mathrm{CB}$ precursor $\left(190 \mathrm{~m}^{2} / \mathrm{g}\right)$. Both materials $\left({ }^{0.9} \mathrm{Pd} / \mathrm{CB}\right.$ and $\left.\mathrm{CB}\right)$ possess largely 
superimposable isothermal linear profiles and account for classical macroporous networks (Figure 4B and Table S1).

To complement the ${ }^{0.9} \mathrm{Pd} / \mathrm{CB}$ characterization, the metallic surface of Pd nanosheets was determined through a $\mathrm{CO}$ chemisorption experiment (Table $\mathrm{S} 1$ ). To this aim, the sample was preliminary treated under vacuum at $623 \mathrm{~K}$ for $15 \mathrm{~min}$ and subsequently reduced under a constant $\mathrm{H}_{2}$ stream at the same temperature for two hours, assuming a resistance to particles sintering under these conditions. ${ }^{45}$ After cooling the sample to $308 \mathrm{~K}$ under Ar, CO chemisorption was carried out under static conditions and Pd dispersion was determined assuming a 1:2 CO-to-Pd stoichiometry. ${ }^{24,25,46}$ The obtained metal dispersion $(2,12 \%)$, the crystallite size $(52.8 \mathrm{~nm})$ and the metal active area $\left[9.5 \mathrm{~m}^{2} / \mathrm{g}(\right.$ metal $\left.)\right]$ are in good agreement with the large nanosheet-shaped Pd deposits. ${ }^{47}$

Next sections are dedicated to the semi-hydrogenation (or partial reduction) of aliphatic/aromatic alkynes using ${ }^{0.9} \mathrm{Pd} / \mathrm{CB}$ as catalyst under mild reaction conditions. Semihydrogenation is a challenging catalytic process of great relevance from an industrial viewpoint. It also enables a complete catalyst screening in a key catalytic transformation while offering useful hints to the optimization of the catalyst process design ${ }^{48}$ and its hydrogenation performance. ${ }^{49}$

\subsection{Selective hydrogenation of linear alkynes}

${ }^{0.9} \mathrm{Pd} / \mathrm{CB}$ was investigated as catalyst for the selective hydrogenation of linear alkynes under mild conditions. To this aim, 1-heptyne was initially selected as a model substrate and its conversion was followed at room temperature and ambient pressure for the proper reaction time. During the whole hydrogenation process, $\mathrm{H}_{2}(5 \mathrm{~mL} / \mathrm{min})$ was continuously fed as to maintain its concentration in solution constant. For the sake of comparison, the commercially available ${ }^{10} \mathrm{Pd} / \mathrm{AC}$ was employed as catalyst under identical conditions, using almost the same active phase loading $(\approx 0.6 \mathrm{~mol} . \%$ of $\mathrm{Pd} v s$. substrate). For both catalysts, activities measured 
at the most representative conversion times were expressed by the catalyst turn-over-number (TON) in terms of (mol of alkyne converted to alkene $) \cdot\left(\mathrm{mol}_{\mathrm{Pd}}\right)^{-1}$.

The hydrogenation performance of the two catalytic systems at work along with the relative products distribution over time are reported in Figures $5 \mathrm{~A}$ and $5 \mathrm{~B}$, respectively. As expected, the higher the surface density of active metal sites $\left({ }^{10} \mathrm{Pd} / \mathrm{AC}>{ }^{0.9} \mathrm{Pd} / \mathrm{CB}\right)$ the faster the alkyne hydrogenation kinetics. Anyway, ${ }^{0.9} \mathrm{Pd} / \mathrm{CB}$ shows a markedly higher selectivity towards the target 1-heptene, whose value ranks constantly over $97 \%$ till $40 \%$ of substrate conversion and slightly decreases down to $93 \%$ once 1-heptyne conversion is completed (> 99\% after 50 min; TON: 153). On the other hand, selectivity towards 1-heptene goes down much faster in the presence of ${ }^{10} \mathrm{Pd} / \mathrm{AC}$ as catalyst and reaches $74 \%$ when all 1-heptyne is consumed (> 99\% after $\sim 40 \mathrm{~min} ;$ TON: 122). Whatever the catalytic system at work, once all triple bond is consumed, 1-heptene undergoes rapid thermodynamic isomerization to give (E/Z)-diastereomeric mixtures of 2- and 3-heptenes along with the completely saturated hydrocarbon ( $n$-heptane).
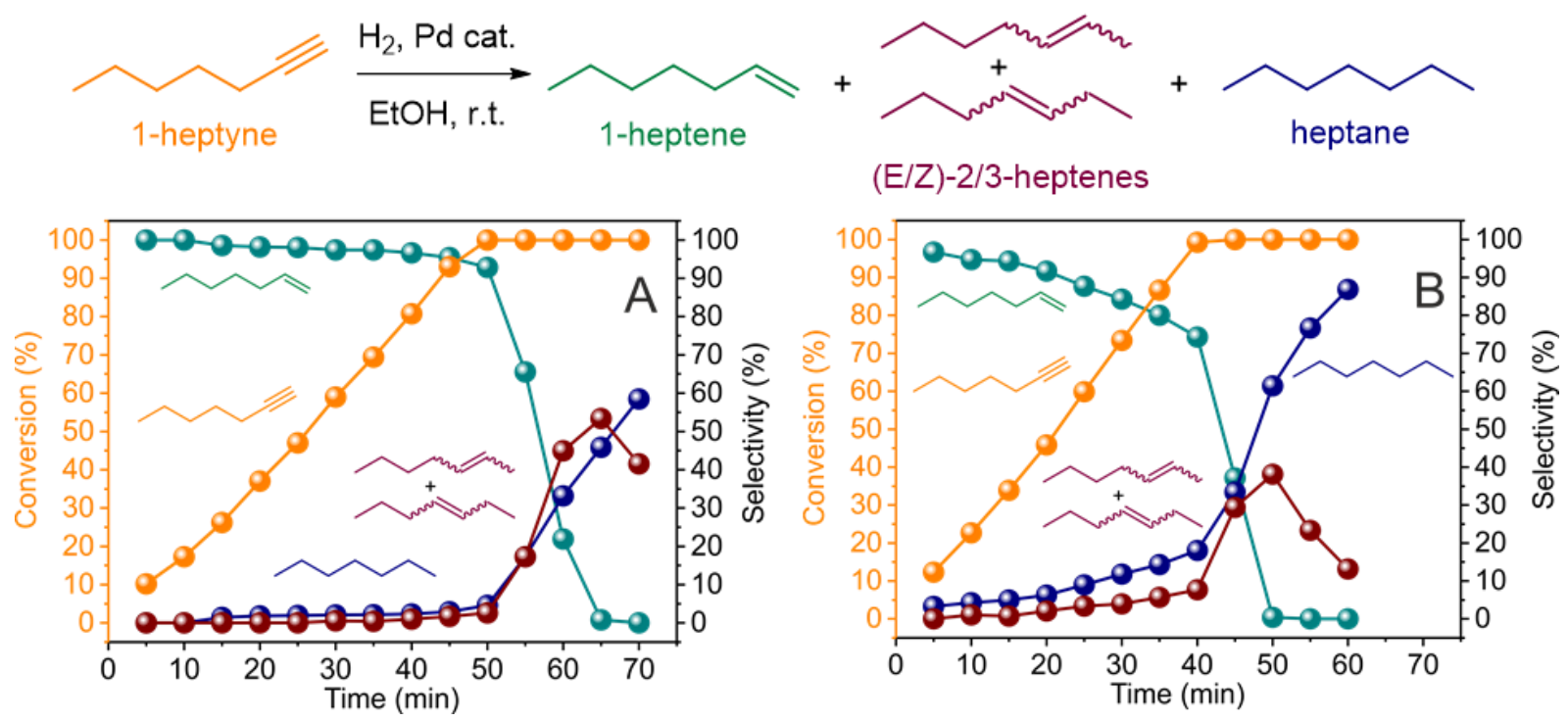

Figure 5. 1-Heptyne hydrogenation with (A) ${ }^{0.9} \mathrm{Pd} / \mathrm{CB}(100 \mathrm{mg})$, (B) ${ }^{10} \mathrm{Pd} / \mathrm{AC}(9.3 \mathrm{mg})$ as catalysts; - -1 -heptyne conversion; - -1 -heptene selectivity; - -2 - and 3-heptene selectivity; - $n$-heptane selectivity. Other reaction conditions: 1-heptyne $(1.52 \mathrm{mmol})$; EtOH $(20 \mathrm{~mL})$; $\mathrm{H}_{2}$ flow rate: $5.0 \mathrm{~mL} / \mathrm{min}$; room temperature, $600 \mathrm{rpm}$. 
Given the equal Pd-loading ( 0.6 mol.\% vs. 1-heptyne) in the two catalytic trials, the higher 1-heptene selectivity observed with ${ }^{0.9} \mathrm{Pd} / \mathrm{CB}$ was likely ascribed to the inherent morphology of the metallic active phase. The presence of large and thin Pd-nanosheets coating the surface of carbon grains was supposed to play an important role in the alkyneadsorption, reduction and alkene-desorption sequence. The shapeless microstructure of a straightforwardly prepared palladium catalyst was found to reduce the occurrence of undesired over-hydrogenation paths responsible of a further reduction of the targeted alkene intermediate. To the best of our knowledge, there are no precedents in the literature for shapeless Pd-nanosheets supported on $\mathrm{CB}$ as selective catalysts for the semi-hydrogenation of terminal alkynes. Worthy of note, similar outcomes in the liquid-phase hydrogenation of 1alkynes have recently been described in combination with morphologically well-defined Pdsingle-atom (SAA) and Pd-alloy single-atom catalysts. ${ }^{50,51}$

Although these authors are aware that any comparison with related heterogeneous systems from the state-of-the-art is hard to be exhaustively addressed due to the different experimental conditions used (catalyst synthesis and composition, nature of active phase carrier and operational conditions: batch vs. continuous mode), the analysis of literature results (Table 1), selected among the most representative papers, unveils the excellent performance of our ${ }^{0.9} \mathrm{Pd} / \mathrm{CB}$ catalyst in the process.

Table 1. Liquid-phase semi-hydrogenation of 1-alkyne with most representative $\mathrm{Pd}$ and $\mathrm{Pd}$ alloy catalysts from the literature.

\begin{tabular}{|c|c|c|c|c|c|c|c|c|c|c|}
\hline$\underset{\Xi}{\stackrel{\Xi}{E}}$ & $\begin{array}{l}{[\mathrm{wt} . \%]} \\
\text { Catalyst }\end{array}$ & 1-Alkyne & Solvent & $\begin{array}{c}T \\
(\mathbf{K})\end{array}$ & $\begin{array}{c}\mathbf{P} \\
\text { (bar) }\end{array}$ & $\begin{array}{c}\mathbf{T} \\
(\mathbf{m i n})\end{array}$ & $\begin{array}{c}\text { Conv. } \\
(\%)^{\mathrm{a}}\end{array}$ & $\begin{array}{c}\text { Select. } \\
(\%)^{\mathrm{a}}\end{array}$ & TON $^{b}$ & Ref. \\
\hline 1 & {$[1.0]$} & 1-heptyne & \multirow{4}{*}{$\mathrm{EtOH}$} & \multirow{4}{*}{295} & \multirow{4}{*}{1} & 40 & 80 & 97 & 129 & \multirow{4}{*}{$\begin{array}{l}\text { This } \\
\text { work }\end{array}$} \\
\hline 1 & ${ }^{0.9} \mathrm{Pd} / \mathrm{CB}$ & 1-neptyne & & & & 50 & $>99$ & 93 & 153 & \\
\hline \multirow{2}{*}{2} & {$[1.0]$} & \multirow{2}{*}{ 1-heptyne } & & & & 25 & 60 & 87 & 87 & \\
\hline & ${ }^{10} \mathrm{Pd} / \mathrm{AC}$ & & & & & 40 & $>99$ & 74 & 122 & \\
\hline 3 & $\begin{array}{l}{[0.5]} \\
{[\mathbf{P d}] \mathbf{m p g}-\mathbf{C}_{3} \mathbf{N}_{4}{ }^{c}}\end{array}$ & 1-hexyne & $\begin{array}{l}\text { Toluene } \\
\text { or THF }\end{array}$ & 343 & 5 & - & - & $\sim 88^{\mathrm{d}}$ & n.d. & 50 \\
\hline \multirow[b]{2}{*}{4} & [0.008 Pd] [3.8 & \multirow[b]{2}{*}{ 1-hexyne } & \multirow[b]{2}{*}{$\mathrm{EtOH}$} & \multirow[b]{2}{*}{298} & \multirow[b]{2}{*}{5} & 80 & 50 & 82 & n.d. & \multirow[b]{2}{*}{51} \\
\hline & $\begin{array}{l}\left.\mathrm{Au} / \mathrm{SiO}_{2}\right] \\
\mathbf{P d A u}-\mathbf{S A A} / \mathrm{SiO}_{2}{ }^{\mathrm{c}}\end{array}$ & & & & & $>150$ & 100 & 82 & n.d. & \\
\hline
\end{tabular}


${ }^{a}$ Alkyne conversion and 1-alkene selectivity were determined by GC analysis. ${ }^{\mathrm{b}}$ Turnover number expressed as (mol of alkyne converted to alkene) $\left(\text { mol }_{\mathrm{Pd}}\right)^{-1}{ }^{\mathrm{c}}$ Single-atom (SA) Pdcatalysts. ${ }^{\mathrm{d}}$ Catalysis was carried out in a continuous-flow three-phase reactor and selectivity refers to the average value over a long-term run $(20 \mathrm{~h})$ with a mean productivity of $1.410^{3}$ mol of 1-hexene produced per mol of Pd per $\mathrm{h}$.

López and Pérez-Ramírez have described a Pd single-site (SS) catalyst obtained by anchoring the metal atoms into the cavities of a mesoporous graphitic carbon nitride. ${ }^{50}$ They successfully exploited their catalyst in a continuous-flow reactor for the three-phase hydrogenation of alkynes and nitroarenes with high activity and products selectivity ( $88 \%$ to 1-hexene for a $20 \mathrm{~h}$ catalytic run at $343 \mathrm{~K}$ and 5 bar of $\mathrm{H}_{2}$ ) compared to nanoparticles-based benchmark catalysts (Table 1, entry 3). An additional in-silico effort from these authors highlighted the importance of atomically dispersed Pd-sites as to ensure high activity and product selectivity in the process. Later, Flytzani-Stephanopoulos and co-workers reported on a sequential reduction method for the $\mathrm{SiO}_{2}$ decoration with PdAu SAA (Single-Atom Alloy) to be employed as effective and stable systems for the model hydrogenation of 1-hexyne to 1hexene. ${ }^{51}$ Their optimized conditions, at room temperature and 5 bar of $\mathrm{H}_{2}$, afforded a 1hexene selectivity as high as $82 \%$ once all starting triple bond was consumed (Table 1, entry 4).

Despite the undoubtful relevance of these seminal contributions, our simplest but effective approach to the generation of shapeless heterogeneous catalysts for the process along with the outstanding results in the semi-hydrogenation reaction (Table 1, entry 1), leave more than a simple doubt on the urgency of sophisticated and wasteful synthetic procedures applied to the design of effective catalysts for this application.

In an additional trial, ${ }^{0.9} \mathrm{Pd} / \mathrm{CB}$ was scrutinized as catalyst for the selective hydrogenation of an internal alkyne. To this aim, the model 3-hexyne underwent hydrogenation under the same mild conditions applied above for the terminal alkyne. Once again, a proper amount of the benchmark ${ }^{10} \mathrm{Pd} / \mathrm{AC}$ was used in the process for the sake of comparison. As Figure $6 \mathrm{~A}$ and 
B show, ${ }^{0.9} \mathrm{Pd} / \mathrm{CB}$ was an extremely selective hydrogenation catalyst to give $97 \%$ of (Z)-3hexene when all alkyne was consumed (> 99\% after 50 min; TON: 160) (Figure 6A). Given the less (thermodynamically) favorable double-bond "chain walking" to afford (E/Z)-2hexene or 1-hexene, isomerization was deeply inhibited. Moreover, the more sterically crowded double-bond environment in (Z)-3-hexene, made harder its further hydrogenation to the saturated hydrocarbon even after several minutes from the complete alkyne conversion.

At odds with the products distribution recorded in the 1-heptyne hydrogenation [1heptene selectivity dropped from 93 down to $22 \%$ after 10 minutes from the complete alkyne consumption (Figure 6A, $60 \mathrm{~min}$ )], selectivity to 3-hexene passed from 97\% (after $50 \mathrm{~min}$ ) down to $91 \%$ after the same time ( $10 \mathrm{~min})$ from the complete 3-hexyne conversion. Such a behavior has already been observed with the Lindlar catalyst ${ }^{52}$ once alkyne hydrogenation affords internal alkenes instead of terminal ones. Noteworthy, the benchmark ${ }^{10} \mathrm{Pd} / \mathrm{AC}$ gave (Z)-3-hexene with a selectivity of $87 \%$ after complete consumption of the internal alkyne ( $35 \mathrm{~min}$; TON: 144). Most importantly, selectivity decreases faster from $87 \%$ down to $38 \%, 25$ min after the complete alkyne conversion, with the 3-hexene over-hydrogenation to $n$-hexane being the dominant side-process (Figure $6 \mathrm{~B})$. The influence of hydrogen flow rate $(\mathrm{mL} / \mathrm{min}$ ) on the selective 3-hexyne hydrogenation catalyzed by ${ }^{0.9} \mathrm{Pd} / \mathrm{CB}$ was finally investigated for the sake of completeness and results are presented in Figure S9 and summarized in Table S2. 

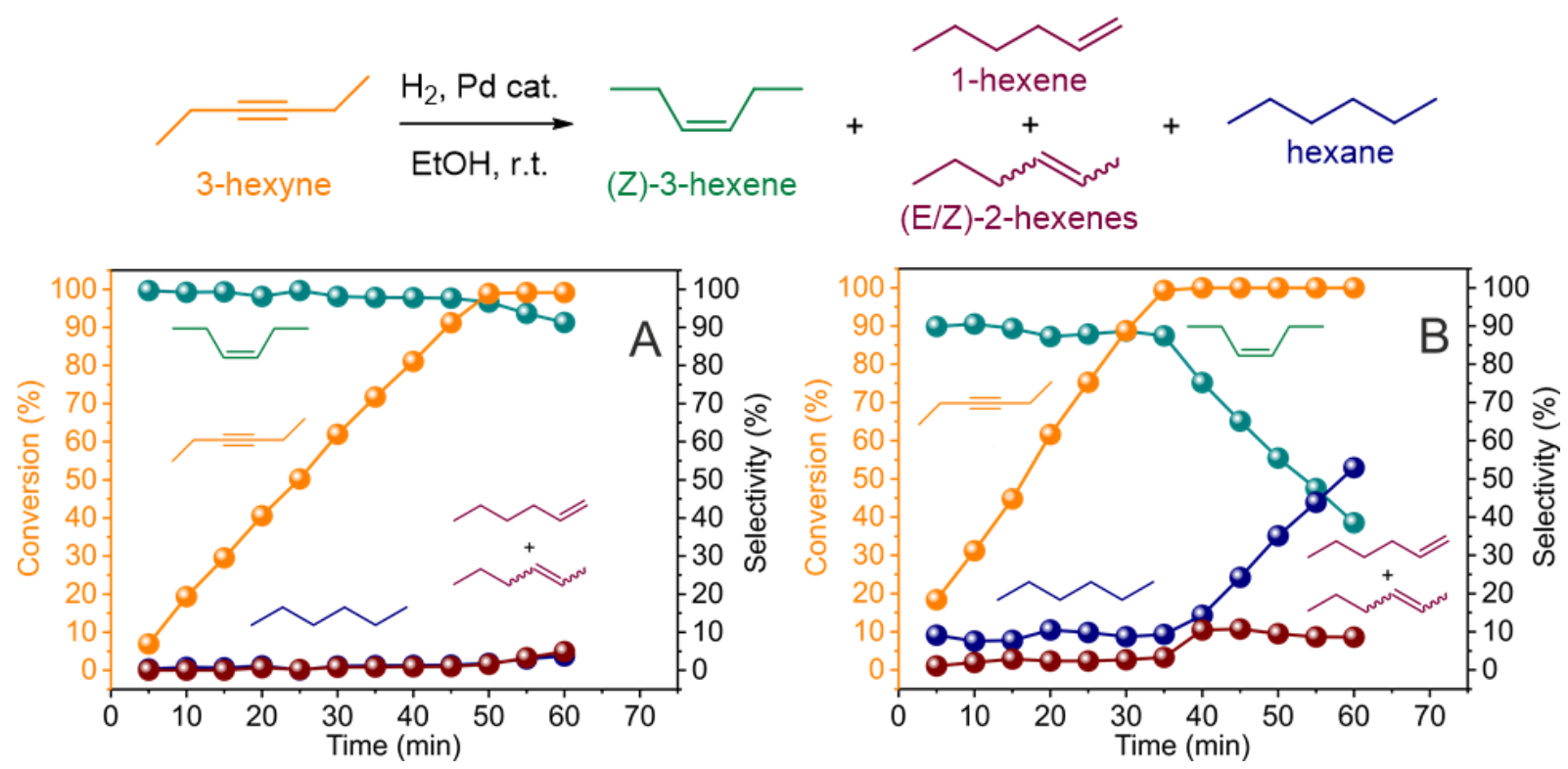

Figure 6. 3-Hexyne hydrogenation with (A) ${ }^{0.9} \mathrm{Pd} / \mathrm{CB}(100 \mathrm{mg})$, (B) ${ }^{10} \mathrm{Pd} / \mathrm{AC}(10 \mathrm{mg})$ as catalysts; - -3 -hexyne conversion; - - 3-hexene selectivity; - -1 - and 2-hexene selectivity; - $-n$-hexane selectivity. Other reaction conditions: 3-hexyne (1.52 mmol); EtOH (20 mL); $\mathrm{H}_{2}$ flow rate: $5.0 \mathrm{~mL} / \mathrm{min}$; room temperature, $600 \mathrm{rpm}$.

A hydrogen flow decrease by $50 \%$ (from 5.0 to $2.5 \mathrm{~mL} / \mathrm{min}$ ) affects only negligibly the hydrogenation selectivity (99\% vs. 98\%) of the process and causes only a slight increase of the reaction time to $55 \mathrm{~min}$ to carry out the reaction to completeness (Figure S9A and Table S2). On the other hand, increased hydrogen flows (i.e. $13.0 \mathrm{~mL} / \mathrm{min}$ ) allow maintaining markedly high selectivity values $(98 \%)$ towards the targeted internal alkene and reducing appreciably the reaction time necessary to bring the reaction up to completeness (40 min $v s$. $50 \mathrm{~min}$ for $5.0 \mathrm{~mL} / \mathrm{min}$ ) (Figure $\mathrm{S} 9 \mathrm{~B}$ and Table $\mathrm{S} 2$ ), thus optimizing the catalyst performance.

\subsection{Selective hydrogenation of aromatic alkynes}

${ }^{0.9} \mathrm{Pd} / \mathrm{CB}$ was finally studied as a selective, robust and re-usable (vide infra) catalytic system for the semi-hydrogenation of phenylacetylene (PA) to styrene (ST). This process is of great relevance because this aromatic alkyne is an unwanted component of gaseous reagent streams employed in polystyrene production plants and whose removal (to a concentration 
lower than $10 \mathrm{ppm}$ ) is mandatory in order to prevent the deactivation/poisoning of polymerization catalysts. $^{5}$

The reaction was carried out under conditions similar to those reported above for aliphatic compounds. A complete selectivity to styrene (ST) was maintained throughout the first half an hour of reaction and till PA conversion was lower than 50\%. Afterwards, selectivity slightly drops down to $96 \%$ and lies constantly on that value till complete alkyne consumption (e.g. $98 \%$ of PA converted after 55 min of reaction with a ST selectivity of $96 \%$ - TON: 157 - See Figure 7A). Satisfyingly, ethylbenzene (EB) started to be produced appreciably only after complete PA conversion into ST. With the benchmark ${ }^{10} \mathrm{Pd} / \mathrm{AC}, \mathrm{ST}$ selectivity was constantly lower than $100 \%$ already after few minutes of the catalyst on run. Alkyne consumption proceeded faster with the commercially available system to get $96 \%$ PAto-ST conversion with an alkene selectivity of $95 \%$ after 30 min only (TON: 152) (Figure 7B). Anyway, selectivity was lost faster after all PA was consumed with EB formation taking place twice faster on ${ }^{10} \mathrm{Pd} / \mathrm{AC}$ than on ${ }^{0.9} \mathrm{Pd} / \mathrm{CB}$ (Figure 7B).

Aimed at further highlighting the effective aptitude of ${ }^{0.9} \mathrm{Pd} / \mathrm{CB}$ to hydrogenate selectively PA into ST, we performed the catalytic process starting from a mixture of PA and ST with the latter being in a nearly two-fold molar excess (Figure 7C). During the first 20 min on run, we observed a totally selective conversion of the minority reagent into ST without any appreciable competition of the hydrogenation on latter to give EB. Remarkably, ${ }^{0.9} \mathrm{Pd} / \mathrm{CB}$ maintained a complete chemoselectivity in the hydrogenation process till complete consumption of the alkyne in the mixture (after $c a .20$ min). ST hydrogenation to EB occurs appreciably only afterwards (Figure 7C).

These promising results prompted us to compare the performance of our straightforwardly prepared ${ }^{0.9} \mathrm{Pd} / \mathrm{CB}$ catalyst with more sophisticated Pd-systems from the literature (Table 2). ${ }^{0.9} \mathrm{Pd} / \mathrm{AC}$ in $\mathrm{PA}$ semi-hydrogenation outperforms catalytic systems of the 
state-of-the-art as those reported by Cazorla-Amorós et al. ${ }^{5,53}$ (Table 2, entry 1 vs. 2). These authors described a series of carbon-supported $[\mathrm{CB}$, activated carbon (AC) and carbon nanotubes - CNTs] Pd catalysts at a variable metal loading (0.7-2.2 wt.\%), prepared by the reduction-by-solvent method. ${ }^{5}$ Besides adopting more complicated experimental procedures for the reduction of the Pd precursor to colloidal nanoparticles, these systems show additional drawbacks: a $\mathrm{H}_{2}$ flow of $30 \mathrm{~mL} / \mathrm{min}$, a reaction temperature as high as $323 \mathrm{~K}$ and reaction times between 350 and 520 min were required to obtain a complete PA consumption and a ST selectivity close to $96-97 \%$.

As Table 2 illustrates, the catalytic performance of ${ }^{0.9} \mathrm{Pd} / \mathrm{CB}$ (Entry 1) compares well or even outperforms those of the most representative catalytic systems of the state-of-the-art, whose preparation typically implies more complex synthetic paths aimed at the fine tailoring of the active phases ${ }^{54-56}$ (including the Lindlar catalyst ${ }^{54,57,58}$ ) (Entries 3-10), or the production of highly dispersed, size and shape-controlled palladium-based nanocomposites ${ }^{57-}$ ${ }^{63}$ (Entries 11-17) up to Pd single-atom (SA) ${ }^{64-66}$ (Entry 18-19) catalysts. 

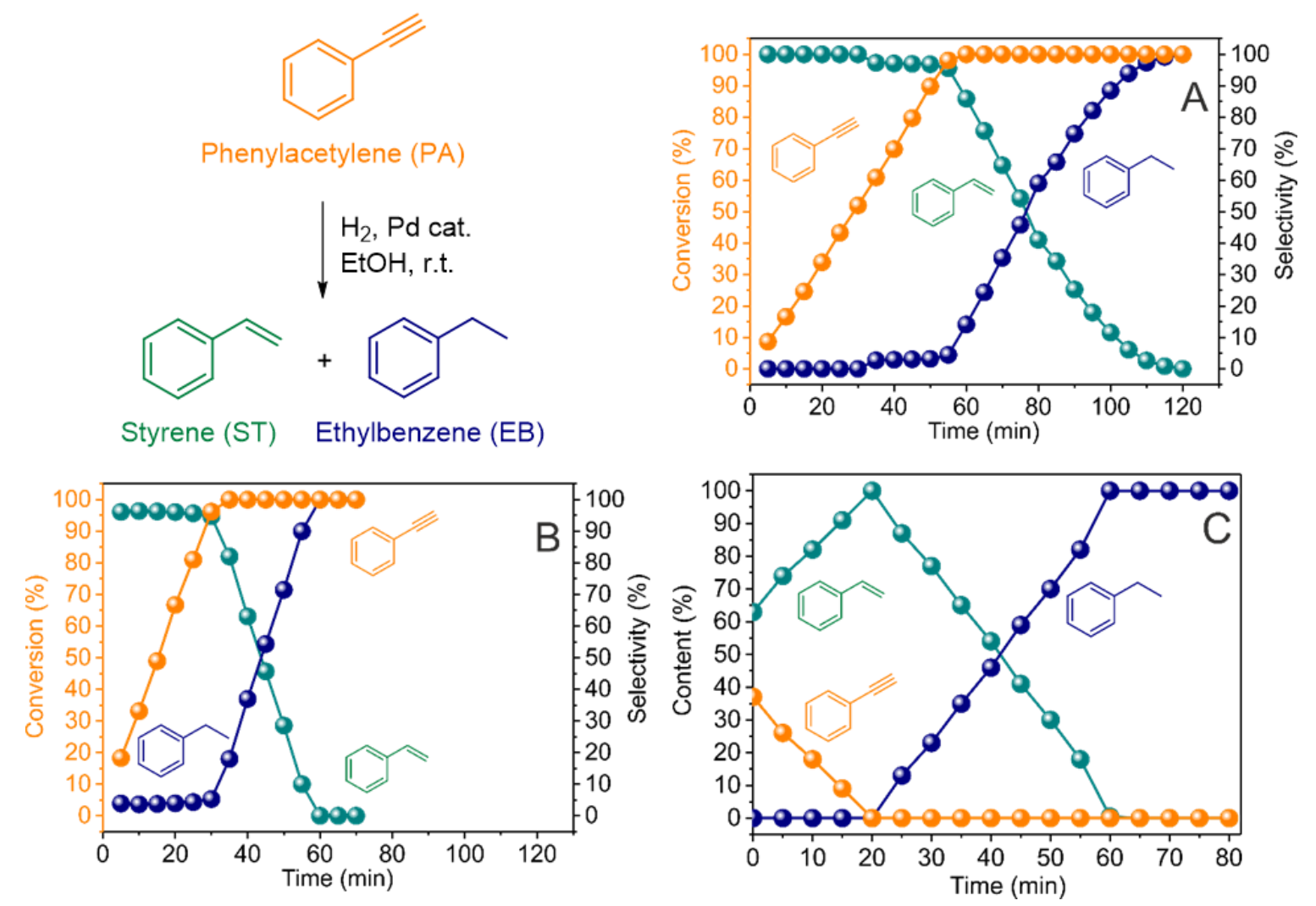

Figure 7. Phenylacetylene (PA) hydrogenation with (A) ${ }^{0.9} \mathrm{Pd} / \mathrm{CB}(100 \mathrm{mg}),(\mathrm{B}){ }^{10} \mathrm{Pd} / \mathrm{AC}(10$ $\mathrm{mg}$ ) as catalysts; -O-PA conversion; - - ST selectivity; - - EB selectivity. Other reaction conditions: PA $(1.52 \mathrm{mmol})$; $\mathrm{EtOH}(20 \mathrm{~mL}) ; \mathrm{H}_{2}$ flow rate: $5.0 \mathrm{~mL} / \mathrm{min}$; room temperature, $600 \mathrm{rpm}$. (C) ${ }^{0.9} \mathrm{Pd} / \mathrm{CB}(100 \mathrm{mg})$ hydrogenation of a $37 / 63$ mixture of PA and ST. Other reaction conditions: PA $(0.61 \mathrm{mmol})$; ST $(0.91 \mathrm{mmol})$; EtOH $(20 \mathrm{~mL}) ; \mathrm{H}_{2}$ flow rate: 5.0 $\mathrm{mL} / \mathrm{min}$; room temperature, $600 \mathrm{rpm}$.

Table 2. Liquid-phase hydrogenation catalysts for the selective PA-to-ST reduction.

\begin{tabular}{|c|c|c|c|c|c|c|c|c|}
\hline Entry & Catalyst & Solvent & $\begin{array}{c}\boldsymbol{T} \\
(\mathbf{K})\end{array}$ & $\begin{array}{c}\mathbf{P} \\
\text { (bar) }\end{array}$ & $\begin{array}{c}\mathbf{T} \\
(\mathrm{min})\end{array}$ & $\begin{array}{c}\text { Conv. } \\
(\%)^{a}\end{array}$ & $\begin{array}{c}\text { Select. } \\
(\%)^{\mathrm{a}}\end{array}$ & Ref. \\
\hline $1^{\mathrm{c}}$ & ${ }^{0.9} \mathrm{Pd} / \mathrm{CB}$ & $\mathrm{EtOH}$ & 298 & 1 & 55 & $>99$ & 96 & $\begin{array}{l}\text { This } \\
\text { work }\end{array}$ \\
\hline $2^{\mathrm{d}}$ & $\mathrm{Pd} / \mathrm{NT}$ or $\mathrm{Pd} / \mathrm{CB}$ or $\mathrm{Pd} / \mathrm{AC}$ & $\mathrm{MeOH}$ & 323 & 1 & $360-520$ & $>99$ & $96-97$ & 5 \\
\hline $3^{\mathrm{e}}$ & $\mathrm{SiO}_{2} @ \mathrm{CuFe}_{2} \mathrm{O}_{4}-\mathrm{Pd}$ & $n$-Hexane & - & 1 & 150 & $98^{\mathrm{b}}$ & $98^{\mathrm{b}}$ & 54 \\
\hline $4^{\mathrm{f}}$ & $\mathrm{Pd} / \mathrm{Ag} @ \mathrm{CeO}_{2}-1.5$ & EtOH & 313 & 15 & 720 & 97 & 99 & 55 \\
\hline $5^{g}$ & $\mathrm{Pd}_{5} \mathrm{Au}_{5} / \mathrm{ZnTi}$ & $\mathrm{EtOH}$ & 318 & 15 & 80 & $>99$ & 93 & 56 \\
\hline $6^{\mathrm{h}}$ & Lindlar catalyst (Aldrich) & $n$-Hexane & - & 1 & 150 & 82 & 92 & 54 \\
\hline $7^{\mathrm{h}}$ & Lindlar catalyst (Aldrich) & $n$-Hexane & - & 1 & 210 & 98 & 76 & 54 \\
\hline $8^{\mathrm{i}}$ & Lindlar catalyst (NHU Co.) & EtOH & 303 & 1 & 270 & 5 & $>99$ & 57 \\
\hline $9^{j}$ & Lindlar catalyst (TCI) & Acetonitrile & 303 & 1 & 60 & 86 & 99 & 58 \\
\hline $10^{\mathrm{j}}$ & Lindlar catalyst (TCI) & Acetonitrile & 303 & 1 & 720 & $>99$ & 76 & 58 \\
\hline $11^{\mathrm{k}}$ & $\mathrm{Pd} / \mathrm{N}, \mathrm{O}-$ carbon & EtOH & 298 & 1 & 90 & $>99$ & 95 & 59 \\
\hline $12^{1}$ & $\mathrm{Pd} / \mathrm{mpg}_{-} \mathrm{C}_{3} \mathrm{~N}_{4}$ & $\mathrm{EtOH}$ & 303 & 1 & 85 & $>99$ & 94 & 57 \\
\hline
\end{tabular}




\begin{tabular}{|c|l|c|c|c|c|c|c|c|}
\hline $13^{\mathrm{m}}$ & MWCNTs-Fe ${ }_{3} \mathrm{O}_{4}-\mathrm{Cu}_{2} \mathrm{O}-\mathrm{Pd}$ & Acetonitrile & 303 & 1 & 90 & $>99$ & 98 & 58 \\
\hline $14^{\mathrm{n}}$ & $\mathrm{CN} @ \mathrm{Pt} / \mathrm{CNTs}$ & $\mathrm{EtOH}$ & 348 & 3 & 100 & $>99$ & 87 & 60 \\
\hline $15^{\mathrm{o}}$ & $\mathrm{Pd} / \mathrm{SPMB}-2.7$ & Acetonitrile & 298 & 1 & 140 & $>99$ & 96 & 61 \\
\hline $16^{\mathrm{p}}$ & $\mathrm{PyC}{ }_{12} \mathrm{~S}-\mathrm{Pd} / \mathrm{VC}$ & $\mathrm{CH}_{2} \mathrm{Cl}_{2}$ & 303 & 1 & 330 & $>99$ & 88 & 62 \\
\hline $17^{\mathrm{q}}$ & $\mathrm{Pd}+\mathrm{PEI}(\mathrm{L}) @ \mathrm{HSS}$ & $\begin{array}{c}\mathrm{MeOH} / 1,4- \\
\text { dioxane }\end{array}$ & 303 & 1 & 270 & $>99$ & 84 & 63 \\
\hline 18 & $\mathrm{Pd}^{\mathrm{s}}-\mathrm{GDY}$ & EtOH & 298 & 2 & 120 & $>99$ & 99.3 & 64 \\
\hline $19^{\mathrm{r}}$ & $\mathrm{Pd}_{0.18} \mathrm{Cu}_{15} / \mathrm{Al}_{2} \mathrm{O}_{3}$ & $n$-Hexane & 298 & 6.9 & 480 & 90 & 94 & 65 \\
\hline
\end{tabular}

${ }^{\mathrm{a}} \mathrm{PA}$ conversion and ST selectivity were determined by GC analysis. ${ }^{\mathrm{b}}$ Values confirmed by ${ }^{1} \mathrm{H}$ NMR spectroscopy. Pd-loading in the catalytic materials: ${ }^{\mathrm{c}} 0.924 \mathrm{wt} . \%$; ${ }^{\mathrm{d}} 0.7-2.2 \mathrm{wt} . \%{ }^{\mathrm{e}}$ 4.15 wt. $\%$; ${ }^{\mathrm{f}} 8$ wt. $\% ;{ }^{\mathrm{g}}$ Total content of noble metals: $93 \mu \mathrm{mol} / \mathrm{g}(\mathrm{ZnTi}) ;{ }^{\mathrm{h}} 5$ wt. $\% ;{ }^{\mathrm{i}} 1 \mathrm{wt} . \% ;{ }^{\mathrm{j}} 5$ wt. $\% ;{ }^{k} 1.64$ wt. $\% ;{ }^{1} 5.64$ wt. $\% ;{ }^{\mathrm{m}} 1.67 \mathrm{wt} . \% ;{ }^{\mathrm{n}} 2.3 \mathrm{wt} . \% ;{ }^{\circ} \mathrm{S} / \mathrm{Pd}$ mol ratio $=2.7 ;{ }^{\mathrm{p}} 1 \mathrm{wt} . \% ;{ }^{\mathrm{q}} 0.5$ mol \%; 0.5 mol \%; ${ }^{\mathrm{r}} \mathrm{Pd}$-loading: 0.18 at.\%

\subsection{Leaching test, catalyst recovery and recycling.}

One key feature associated to the use of relatively large Pd-nanosheets wrapped to carbon grains is their reduced surface mobility throughout long term catalytic runs.

As a matter of fact, alterations of the catalyst active phase are deeply mitigated. Hence,the catalyst performance is preserved over long term cycles and environmental risks associated to nano-objects leaching phenomena are reduced. Nanoparticles leaching can be also responsible for the occurrence of side-processes promoted by free-particles suspended in the liquid medium whose catalytic action alters the effective heterogeneous nature of the process.

In order to verify the truly heterogeneous nature of the catalysis, a leaching test was conducted by filtering the ${ }^{0.9} \mathrm{Pd} / \mathrm{CB}$ catalyst from the reaction medium after running the 3 hexyne hydrogenation for 50 min under a continuum $\mathrm{H}_{2}$ stream at the flow rate of $5 \mathrm{~mL} / \mathrm{min}$. The GC analysis of filtered mother liquors confirmed a complete alkyne conversion (> $99 \%$ ) with a 3-hexene selectivity of $98 \%$. To assess the catalytic power of the filtered mother liquors and thus to rule out metal leaching phenomena and the co-existence of alternative catalytic paths, the ${ }^{0.9} \mathrm{Pd} / \mathrm{CB}$-free ethanol solution was then treated again with 3 -hexyne $(1.52$ mmol) and maintained under the same conditions as above, i.e. bubbled with a $5.0 \mathrm{~mL} / \mathrm{min}$ flow of $\mathrm{H}_{2}$ at r.t. for further $50 \mathrm{~min}$. GC analysis of the solution before and after $\mathrm{H}_{2}$ treatment 
did not show any appreciable change in the 3-hexyne/3-hexene ratio, thus excluding the presence of atomically leached and catalytically active $\mathrm{Pd}$ species in the liquid reaction medium. In a separate experiment, ${ }^{0.9} \mathrm{Pd} / \mathrm{CB}$ stability and re-usability in catalysis was investigated through successive recovery/recycling tests where the catalyst was recovered by centrifugation, separated by the liquid supernatant, washed with pure ethanol and evaporated to dryness in an oven at $383 \mathrm{~K}$ before being reused in catalysis. As Figure S10 shows, ${ }^{0.9} \mathrm{Pd} / \mathrm{CB}$ proved to be extremely stable over successive catalytic tests, giving 3-hexene with a mean selectivity of $97 \%$ and a conversion varying between 98.5 and > 99\% over three consecutive runs of 50 min each.

These results confirm the remarkable catalyst stability under the operative conditions as well as the reduced mobility of Pd-nanosheets whose extensive interaction with the surface of carbon grains reduces if not suppresses leaching phenomena. This result additionally strengthens the relevance of the nanosheet morphology of Pd-deposits prepared by the ultrasonication method. Indeed, there are only very few examples in the literature that boast the complete suppression of the active-phase leaching, ${ }^{52}$ particularly when catalytically active nano-objects are directly engaged in the semi-hydrogenation process. ${ }^{67-70}$ After three catalytic cycles, the recovered catalyst was analyzed through TEM analysis and its morphology was compared with that of the fresh one. As Figure S11 shows, Pd-active phase retains its pristine microstructure made of irregularly shaped and largely carbon entangled thin nanosheets (Figures S10A-C). At higher magnifications, the underlying disordered structure of carbon black is clearly identified below that of ultra-thin and ordered crystallographic planes of palladium deposits (Figure S11D).

\section{Conclusion}


The effects of ultrasound are the consequence of the cavitation phenomenon, hence the formation, the growth and the collapse of gaseous microbubbles in a liquid phase or at the liquid-solid interphase. The intense mechanical, thermal and chemical local effects due to the bubbles collapse make sonochemistry a valuable and innovative approach to produce catalytic materials in a more eco-sustainable way. In this contribution we have described the simple, wasteless and reproducible approach to the reductant-free generation of $\mathrm{Pd}^{0}$ deposits in the form of ultra-thin nanosheets fixed to the grains of the carbon black support. The unusual morphology of the metal deposits has been thoroughly investigated and the reduction mechanism at work in the process has been postulated. In spite of the unconventional shape of the metal deposits, these composites have been scrutinized as catalysts for the highly efficient and selective heterogeneous alkyne-to-alkene hydrogenation of aliphatic and aromatic compounds. Quite unexpectedly, the carbon supported Pd nanosheets have shown comparable or even higher performance in the process compared to benchmark systems like the Lindlar catalyst or ${ }^{10} \mathrm{Pd} / \mathrm{AC}$, including other more costly and less easy to be prepared nanoparticlebased or single-atom-based catalysts of the state-of-the-art.

Catalytic outcomes lead us to conclude that the high alkene selectivity observed with ${ }^{0.9} \mathrm{Pd} / \mathrm{CB}$ (from 93 up to $97 \%$ depending on the starting alkyne at its conversion > 99\%) is likely to be ascribed to the morphology of the metallic active phase. The presence of large and thin Pd-nanosheets is supposed to play an important role in the alkyne-adsorption, reduction and alkene-desorption sequence, thus limiting the occurrence of undesired overhydrogenation paths.

To the best of our knowledge, this is a unique example of a hydrogenation catalyst for the semi-alkyne-to-alkene reduction that goes on an opposite direction with respect to the more classical approaches based on the size and shape control at the nanoscale of metal deposits in the catalyst design. Although electronic effects raising from the support-active phase 
interactions on the catalytic behavior (i.e. palladium interactions with the O-containing groups on the support) cannot be ruled out, metallic nanosheets fixed to the support along with their large size deeply mitigate the risks associated to the surface mobility of the catalyst active phase, preserve the catalyst performance on long term runs and reduce environmental risks associated to nano-objects leaching phenomena.

Additional studies aimed at shaping these powdery catalysts in the form of 3D open-cell networks and their application in fixed-bed flow reactors are currently under study and will be reported elsewhere soon.

\section{- ASSOCIATED CONTENT}

Supporting Information. The Supporting Information is available free of charge on the ACS Publications website at DOI: $10.1021 /$ acs............

S/TEM micrographs of the ${ }^{0.9} \mathrm{Pd} / \mathrm{CB}$ sample at variable magnifications (before and after catalysis), including those of the plain CB support. 3-hexyne hydrogenation runs at variable $\mathrm{H}_{2}$ flow-rates and XRD profile of ${ }^{0.9} \mathrm{Pd} / \mathrm{CB}$ catalyst. High resolution XPS C $1 s$ core region of the commercial carbon black, Specific Surface Areas and pore volume distribution of catalysts and $\mathrm{CB}(\mathrm{PDF})$.

\section{- AUTHOR INFORMATION}

Corresponding Authors

*E-mail: giambastiani@unistra.fr

*E-mail: vritleng@unistra.fr

*E-mail: cuong.pham-huu@ @unistra.fr

\section{ORCID}

Giuliano Giambastiani: 0000-0002-0315-3286

Vincent Ritleng: 0000-0002-8480-1491 
Cuong Pham-Huu: 0000-0003-3271-019X

Andrea Rossin: 0000-0002-1283-2803

\section{Funding}

Agence Nationale de la Recherche (ANR) project n ANR-16-CE07-0030-01. TRAINER project (ANR-17-MPGA-0017) “Catalysts for Transition to Renewable Energy Future” from the "Make our Planet Great Again" program.

\section{Notes}

The authors declare no competing financial interest.

\section{- ACKNOWLEDGMENTS}

The Agence Nationale de la Recherche (ANR) is gratefully acknowledged for the $\mathrm{PhD}$ fellowship of A.A.K. and its financial support during the project (ANR-16-CE07-0030-01). G.G., C.P.-H. and O.E. would also like to thank the TRAINER project (Catalysts for Transition to Renewable Energy Future) of the "Make our Planet Great Again" program (Ref. ANR-17-MPGA-0017) for support. Mr. Han PENG is gratefully acknowledged for his contribution to revisions experiments.

\section{- REFERENCES and NOTES}

1. Blaser, H.-U.; Schnyder, A.; Steiner, H.; Rössler, F.; Baumeister, P., Selective Hydrogenation of Functionalized Hydrocarbons. In Handbook of Heterogeneous Catalysis, Ertl, G.; Knözinger, H.; Schüth, F.; Weitkamp, J., Eds. Wiley-VCH: Weinheim, 2008; pp 3284-3308.

2. Heller, D.; H., d. V. A.; de Vries, J. G., In Handbook of Homogeneous Hydrogenation, de Vries, J. G.; Elsevier, C. J., Eds. Wiley-VCH: Weinheim, 2007; Vol. 3, pp 1483-1516.

3. Oger, C.; Balas, L.; Durand, T.; Galano, J. M., Are Alkyne Reductions Chemo-, Regio-, and Stereoselective Enough To Provide Pure (Z)-Olefins in Polyfunctionalized Bioactive Molecules? Chem. Rev. 2013, 113, 1313-1350. 
4. Teschner, D.; Vass, E.; Hävecker, M.; Zafeiratos, S.; Schnörch, P.; Sauer, H.; KnopGericke, A.; Schlögl, R.; Chamam, M.; Wootsch, A.; Canning, A. S.; Gamman, J. J.; Jackson, S. D.; McGregor, J.; Gladden, L. F., Alkyne hydrogenation over Pd catalysts: A new paradigm. J. Catal. 2006, 242, 26-37.

5. Domínguez-Domínguez, S.; Berenguer-Murcia, A.; Pradhan, B. K.; Linares-Solano, A.; Cazorla-Amorós, D., Semihydrogenation of phenylacetylene catalyzed by palladium nanoparticles supported on carbon materials. J. Phys. Chem. C 2008, 112, 3827-3834.

6. Venkatesan, R.; Prechtl, M. H. G.; Scholten, J. D.; Pezzi, R. P.; Machado, G.; Dupont, J., Palladium nanoparticle catalysts in ionic liquids: synthesis, characterisation and selective partial hydrogenation of alkynes to Z-alkenes. J. Mater. Chem. 2011, 21, 30303036 .

7. Uberman, P. M.; Costa, N. J. S.; Philippot, K.; Carmona, R. C.; Dos Santos, A. A.; Rossi, L. M., A recoverable Pd nanocatalyst for selective semi-hydrogenation of alkynes: hydrogenation of benzyl-propargylamines as a challenging model. Green Chem. 2014, $16,4556-4574$.

8. Delgado, J. A.; Benkirane, O.; Claver, C.; Curulla-Ferré, D.; Godard, C., Advances in the preparation of highly selective nanocatalysts for the semi-hydrogenation of alkynes using colloidal approaches. Dalton Trans. 2017, 46, 12381-12403.

9. Teschner, D.; Borsodi, J.; Wootsch, A.; Révay, Z.; Hävecker, M.; Knop-Gericke, A.; Jackson, S. D.; Schlögl, R., The roles of subsurface carbon and hydrogen in palladiumcatalyzed alkyne hydrogenation. Science 2008, 320, 86-89.

10. Vilé, G.; Albani, D.; Almora-Barrios, N.; López, N.; Pérez-Ramírez, J., Advances in the Design of Nanostructured Catalysts for Selective Hydrogenation. ChemCatChem 2016, $8,21-33$.

11. Parra da Silva, F.; Fiorio, J. L.; Rossi, L. M., Tuning the catalytic activity and selectivity of Pd nanoparticles using ligand-modified supports and surfaces. ACS Omega 2017, 2, 6014-6022.

12. Zhao, Y.; Fu, G.; Zheng, N., Shaping the selectivity in heterogeneous hydrogenation by using molecular modification strategies: experiment and theory. Catal. Today 2017, 279, $36-44$.

13. Zhao, M.; Ji, Y.; Wang, M.; Zhong, N.; Kang, Z.; Asao, N.; Jiang, W.-J.; Chen, Q., Composition-dependent morphology of bi- and trimetallic phosphides: construction of amorphous $\mathrm{Pd}-\mathrm{Cu}-\mathrm{Ni}-\mathrm{P}$ nanoparticles as a selective and versatile Catalyst. ACS Appl. Mater. Interfaces 2017, 9, 34804-34811. 
14. Markov, P. V.; Bragina, G. O.; Rassolov, A. V.; Baeva, G. N.; Mashkovsky, I. S.; Murzin, V. Y.; Zubavichus, U. V.; Stakheev, A. Y., Pd-Cu catalyst prepared from heterobimetallic $\mathrm{PdCu}_{2}(\mathrm{OAc})_{6}$ : an XRD-EXAFS study and activity/selectivity in the liquid-phase hydrogenation of a $\mathrm{C} \equiv \mathrm{C}$ bond. Mendeleev Commun. 2016, 26, 502-504.

15. Kruppe, C. M.; Krooswyk, J. D.; Trenary, M., Selective hydrogenation of acetylene to ethylene in the presence of a parbonaceous surface layer on a $\mathrm{Pd} / \mathrm{Cu}(111)$ single-atom alloy. ACS Catal. 2017, 7, 8042-8049.

16. Kyriakou, G.; Boucher, M. B.; Jewell, A. D.; Lewis, E. A.; Lawton, T. J.; Baber, A. E.; Tierney, H. L.; Flytzani-Stephanopoulos, M.; Sykes, E. C. H., Isolated metal atom geometries as a strategy for selective heterogeneous hydrogenations. Science 2012, 335, 1209-1212.

17. Zhang, L.; Zhou, M.; Wang, A.; Zhang, T., Selective hydrogenation over supported metal catalysts: from nanoparticles to single atoms. Chem. Rev. 2020, 120, 683-733.

18. Chatel, G., Sonochemistry - New Opportunities for Green Chemistry. World Scientific Publishing Co Pte Ltd: 2017.

19. Suslick, K. S., Sonochemistry. Science 1990, 247, 1439-1445.

20. Vanyorek, L.; Prekob, A.; Hajdu, V.; Muranszky, G.; Fiser, B.; Sikora, E.; Kristaly, F.; Viskolcz, B., Ultrasonic cavitation assisted deposition of catalytically active metals on nitrogen-doped and non-doped carbon nanotubes - A comparative study. J. Mater. Res. Technol. 2020, 9, 4283-4291.

21. Mastronarde, D. N., Dual-axis tomography: an approach with alignment methods that preserve resolution. J. Struct. Biol. 1997, 120, 343-352.

22. Gordon, R.; Bender, R.; Herman, G. T., Algebraic reconstruction techniques (ART) for three-dimensional electron microscopy and x-ray photography. J. Theor. Biol. 1970, 29, 471-481.

23. Messaoudii, C.; Boudier, T.; Schancez Sorzano, C. O.; Marco, S., TomoJ: tomography software for three-dimensional reconstruction in transmission electron microscopy. BMC Bioinf. 2007, 6, 288-292.

24. Murata, K.; Ogura, K.; Ohyama, J.; Sawabe, K.; Yamamoto, Y.; Arai, S.; Satsuma, A., Selective Hydrogenation of Cinnamaldehyde over the Stepped and Plane Surface of Pd Nanoparticles with Controlled Morphologies by CO Chemisorption. ACS Appl. Mater. Interfaces 2020, 12, 26002-26012. 
25. Fagherazzi, G.; Canton, P.; Riello, P.; Pernicone, N.; Pinna, F.; Battagliarin, M., Nanostructural Features of $\mathrm{Pd} / \mathrm{C}$ Catalysts Investigated by Physical Methods: A Reference for Chemisorption Analysis. Langmuir 2000, 16, 4539-4546.

26. Hull, A. W., X-ray crystal analysis of 13 common metals. Phys. Rev. 1921, 17, 571-587.

27. Kelsall, R. W.; Hamley, I.; Geoghegam, M., In Nano Scale Science and Technology. John Wiley \& Sons, Ltd: New York, 2005; p 456.

28. Byrappa, K.; Ohachi, T., In Crystal Growth Technology, Springer: New York, 2003; p 581.

29. Ba, H.; Tuci, G.; Evangelisti, C.; Ceppatelli, M.; Nguyen-Dinh, L.; Dal Santo, V.; Bossola, F.; Nhut, J.-M.; Rossin, A.; Granger, P.; Giambastiani, G.; Pham-Huu, C., The Second Youth of a Metal-Free Dehydrogenation Catalyst: when $\gamma-\mathrm{Al}_{2} \mathrm{O}_{3}$ Meets Coke Under Oxygen and Steam-Free Conditions. ACS Catal. 2019, 9, 9474-9484.

30. Arblaster, J. W., Crystallographic Properties of Palladium. Platinum Metals Rev. 2012, $56,181-189$.

31. Ersen, O.; Florea, I.; Hirlimann, C.; Pham-Huu, C., Exploring nanomaterials with 3D electron microscopy. Mater Today 2015, 8, 395-408.

32. Ersen, O.; Hirlimann, C.; Drillon, M.; Werckmann, J.; Tihay, F.; Pham-Huu, C.; Crucifix, C.; Schlutz, P., 3D TEM characterization of nanometric objects. Sol. State Sci. 2007, 9, 1088-1098.

33. Baaziz, W.; Valette, S.; Gay, A. S.; Hirlimann, C.; Ersen, O., A New Methodology for Quantifying the Surface Crystallography of Particles from their Tomographic Reconstruction: Application to Pd Nanoparticles Embedded in a Mesoporous Silica Shell. ChemCatChem 2020, 12, 4422-4430.

34. Camp, J. E.; Dunsford, J. J.; Dacosta, O. S. G.; Blundell, R. K.; Adams, J.; Britton, J.; Smith, R. J.; Bousfield, T. W.; Fay, M. W., Recyclable glucose-derived palladium(0) nanoparticles as in situ-formed catalysts for cross-coupling reactions in aqueous media. RSC Adv. 2016, 6, 16115-16121.

35. Pratt, C. W.; Cornely, K., In Essential Biochemistry, Third ed.; John Wiley and Sons, Inc.: USA, 2014; p 856.

36. Huang, H.; Yang, X., Synthesis of Chitosan-Stabilized Gold Nanoparticles in the Absence/Presence of Tripolyphosphate. Biomacromolecules 2004, 5, 2340-2346.

37. Veisia, H.; Ozturk, T.; Karmakar, B.; Tamoradi, T.; Hemmati, S., In situ decorated Pd NPs on chitosan-encapsulated $\mathrm{Fe}_{3} \mathrm{O}_{4} / \mathrm{SiO}_{2}-\mathrm{NH}_{2}$ as magnetic catalyst in Suzuki-Miyaura coupling and 4-nitrophenol reduction. Carbohydr. Polym. 2020, 235, 115966 (8). 
38. Wolfson, A.; Levy-Ontman, O., Recent Developments in the Immobilization of Palladium Complexes on Renewable Polysaccharides for Suzuki-Miyaura CrossCoupling of Halobenzenes and Phenylboronic Acids. Catalysts 2020, 10, 136.

39. Kibis, L. S.; Stadnichenko, A. I.; Koscheev, S. V.; Zaikovskii, V. I.; Boronin, A. I., Highly Oxidized Palladium Nanoparticles Comprising $\mathrm{Pd}^{4+}$ Species: Spectroscopic and Structural Aspects, Thermal Stability, and Reactivity. J. Phys. Chem. C 2012, 116, 19342-19348.

40. Yousaf, A. B.; Imran, M.; Farooq, M.; Kasak, P., Interfacial Phenomenon and Nanostructural Enhancements in Palladium Loaded Lanthanum Hydroxide Nanorods for Heterogeneous Catalytic Applications. Sci. Rep. 2018, 8, 4354 (9).

41. Meunier, F. C.; Cardenas, L.; Kaper, H.; Šmíd, B.; Vorokhta, M.; Grosjean, R.; Aubert, D.; Dembélé, K.; Lunkenbein, T., Synergy between Metallic and Oxidized Pt Sites Unravelled during Room Temperature CO Oxidation on Pt/Ceria. Angew. Chem. Int. Ed. 2020, DOI: 10.1002/anie.202013223.

42. Karinshak, K. A.; Lott, P.; Harold, M. P.; O., D., In situ Activation of Bimetallic Pd-Pt Methane Oxidation Catalysts. ChemCatChem 2020, 12, 3712-3720.

43. Shamsiev, R. S.; Finkelshtein, E. I., Adsorption of phenylacetylene and styrene on palladium surface: a DFT study. J. Mol. Model. 2018, 24, 143 (8).

44. Sing, K. S. W.; Everett, D. H.; Haul, R. A. W.; Moscou, L.; Pierotti, R. A.; Rouquérol, J., Reporting Physisorption Data For Gas/Solid Systems with Special Reference to the Determination of Surface Area and Porosity. Pure Appl. Chem. 1985, 57, 603-619.

45. Reddy, G. K.; Ling, C.; Peck, T. C.; Jia, H., Understanding the chemical state of palladium during the direct NO decomposition - influence of pretreatment environment and reaction temperature. $R S C A d v$. 2017, 7, 19645-19655.

46. The 1:2 stoichiometry is more appropriate than $1: 1$ as CO molecules tend to adopt a bridged or threefold orientation when adsorbing on larger Pd particles.

47. It should be pointed out that this characterization does not rigorously apply to the metal active phase (i.e. dual oxidic-metallic nature of palladium) engaged in the semihydrogenation process. Indeed, chemisorption has been carried out on the sample after a complete metal reduction. On the other hand, chemisorption carried out on the unreduced sample (i.e. the freshly prepared ${ }^{0.9} \mathrm{Pd} / \mathrm{CB}$ ) may provide unreliable results, because of the occurrence of adventitious interactions between $\mathrm{Pd}^{\mathrm{II}}$ and the probe molecule.. 
48. Vergunst, T.; Kapteijn, F.; Moulijn, J. A., Optimization of Geometric Properties of a Monolithic Catalyst for the Selective Hydrogenation of Phenylacetylene. Ind. Eng. Chem. Res. 2001, 40, 2801-2809.

49. Huang, X.; Wilhite, B.; McCready, M. J.; Varma, A., Phenylacetylene hydrogenation in a three-phase catalytic packed-bed reactor: experiments and model. Chem. Eng. Sci. 2003, 58, 3465-3471.

50. Vilé, G.; Albani, D.; Nachtegaal, M.; Chen, Z.; Dontsova, D.; Antonietti, M.; López, N.; Pérez-Ramírez, J., A stable single-site palladium catalyst for hydrogenations. Angew. Chem. Int. Ed. 2015, 54, 11265-11269.

51. Liu, J.; Shan, J.; Lucci, F. R.; Cao, S.; Sykes, E. C. H.; Flytzani-Stephanopoulos, M., Palladium-gold single atom alloy catalysts for liquid phase selective hydrogenation of 1hexyne. Catal. Sci. Technol. 2017, 7, 4276-4284.

52. Lu, Y.; Feng, X.; Takale, B. S.; Yamamoto, Y.; Zhang, W.; Bao, M., Highly Selective Semihydrogenation of Alkynes to Alkenes by Using an Unsupported Nanoporous Palladium Catalyst: No Leaching of Palladium into the Reaction Mixture. ACS Catal. 2017, 7, 8296-8303.

53. Domínguez-Domínguez, S.; Berenguer-Murcia, A.; Cazorla-Amorós, D.; LinaresSolano, A., Semihydrogenation of phenylacetylene catalyzed by metallic nanoparticles containing noble metals. J. Catal. 2006, 243, 74-81.

54. Lee, K. H.; Lee, B.; Lee, K. R.; Yi, M. H.; Hur, N. H., Dual Pd and $\mathrm{CuFe}_{2} \mathrm{O}_{4}$ nanoparticles encapsulated in a core/shell silica microsphere for selective hydrogenation of arylacetylene. Chem. Commun. 2012, 48, 4414-4416.

55. Song, S.; Li, K.; Pan, J.; Wang, F.; Li, J.; Feng, J.; Yao, S.; Ge, X.; Wang, X.; Zhang, H., Achieving the trade-off between selectivity and activity in semihydrogenation of alkynes by fabrication of (asymmetrical Pd@Ag Core)@ $\left(\mathrm{CeO}_{2}\right.$ shell) nanocatalysts via autoredox reaction. Adv. Mater. 2017, 29, 1605332.

56. Shen, Y.; Yin, K.; An, C.; Xiao, Z., Design of a difunctional Zn-Ti LDHs supported PdAu catalyst for selective hydrogenation of phenylacetylene. Appl. Surf. Sci. 2018, 456, $1-6$.

57. Deng, D.; Yang, Y.; Gong, Y.; Li, Y.; Xu, X.; Wang, Y., Palladium nanoparticles supported on mpg- $\mathrm{C}_{3} \mathrm{~N}_{4}$ as active catalyst for semihydrogenation of phenylacetylene under mild conditions. Green Chem. 2013, 15, 2525-2531. 
58. Yang, S.; Cao, C.; Peng, L.; Zhang, J.; Han, B.; Song, W., A Pd-Cu $\mathrm{Cu}_{2} \mathrm{O}$ nanocomposite as an effective synergistic catalyst for selective semi-hydrogenation of the terminal alkynes only. Chem. Commun. 2016, 52, 3627-3630.

59. Ji, G.; Duan, Y.; Zhang, S.; Fei, B.; Chen, X.; Yang, Y., Selective semihydrogenation of alkynes catalyzed by Pd nanoparticles immobilized on heteroatom-doped hierarchical porous carbon derived from bamboo shoots. ChemSusChem 2017, 10, 3427-3434.

60. Xia, L.; Li, D.; Long, J.; Huang, F.; Yang, L.; Guo, Y.; Jia, Z.; Xiao, J.; Liu, H., Ndoped graphene confined $\mathrm{Pt}$ nanoparticles for efficient semihydrogenation of phenylacetylene. Carbon 2019, 145, 47-52.

61. Zhang, Y.; Wen, X.; Shi, Y.; Yue, R.; Bai, L.; Liu, Q.; Ba, X., Sulfur-Containing Polymer As a Platform for Synthesis of Size-Controlled Pd Nanoparticles for Selective Semihydrogenation of Alkynes. Ind. Eng. Chem. Res. 2019, 58, 1142-1149.

62. Yoshii, T.; Umemoto, D.; Kuwahara, Y.; Mori, K.; Yamashita, H., Engineering of Surface Environment of Pd Nanoparticle Catalysts on Carbon Support with Pyrene-Thiol Ligands for Semihydrogenation of Alkynes. Appl. Mater. Interfaces 2019, 11, 3770837719.

63. Kuwahara, Y.; Kango, H.; Yamashita, H., Pd Nanoparticles and Aminopolymers Confined in Hollow Silica Spheres as Efficient and Reusable Heterogeneous Catalysts for Semihydrogenation of Alkynes. ACS Catal. 2019, 9, 1993-2006.

64. Yin, X.-P.; Tang, S.-F.; Zhang, C.; Wang, H.-J.; Si, R.; Lu, X.-L.; Lu, T.-B., Graphdiyne-based Pd single-atom catalyst for semihydrogenation of alkynes to alkenes with high selectivity and conversion under mild conditions. J. Mater. Chem. A 2020, 8, 20925-20930.

65. Boucher, M. B.; Zugic, B.; Cladaras, G.; Kammert, J.; Marcinkowski, M. D.; Lawton, T. J.; Sykes, E. C.; Flytzani-Stephanopoulos, M., Single atom alloy surface analogs in $\mathrm{Pd}_{0.18} \mathrm{Cu}_{15}$ nanoparticles for selective hydrogenation reactions. Phys. Chem. Chem. Phys. 2013, 15, 12187-12196.

66. Rivera-Carcamo, C.; Serp, P., Single Atom Catalysts on Carbon-Based Materials. ChemCatChem 2018, 10, 5058-5091.

67. Kobayashi, S.; Miyamura, H., Polymer-incarcerated metal(0) cluster catalysts. Chem. Rec. 2010, 10, 271-290.

68. Hirai, Y.; Uozumi, Y., Clean synthesis of triarylamines: Buchwald-Hartwig reaction in water with amphiphilic resin-supported palladium complexes. Chem. Commun. 2010, 46, 1103-1105. 
69. Yamada, Y. M. A.; Sarkar, S. M.; Uozumi, Y., Self-Assembled Poly(imidazolepalladium): Highly Active, Reusable Catalyst at Parts per Million to Parts per Billion Levels. J. Am. Chem. Soc. 2012, 134, 3190-3198.

70. Yamada, Y. M. A.; Yuyama, Y.; Sato, T.; Fujikawa, S.; Uozumi, Y., A palladium- nanoparticle and silicon- nanowire- array hybrid: a platform for catalytic heterogeneous reactions. Angew. Chem. Int. Ed. 2014, 53, 127-131.

Table of contents graphic

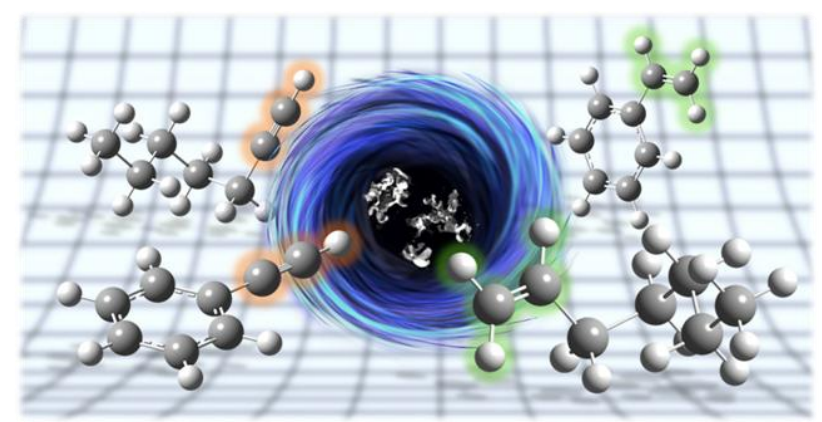

